Supplement of Nat. Hazards Earth Syst. Sci., 17, 409-421, 2017

http://www.nat-hazards-earth-syst-sci.net/17/409/2017/

doi:10.5194/nhess-17-409-2017-supplement

(C) Author(s) 2017. CC Attribution 3.0 License.

(c) (1)

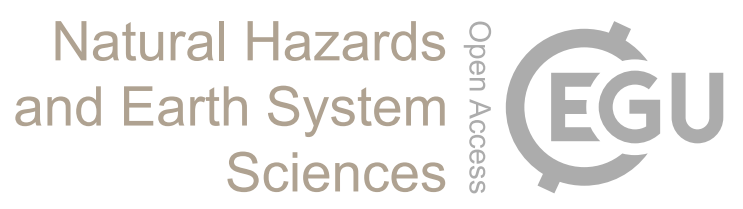

Supplement of

\title{
Assessment of reliability of extreme wave height prediction models
}

Satish Samayam et al.

Correspondence to: Sannasiraj Sannasi Annamalaisamy (sasraj@iitm.ac.in)

The copyright of individual parts of the supplement might differ from the CC-BY 3.0 licence. 
This supplementary material comprises of maps showing the study locations and all the plots of GEV, GPD and P-app model analysis for all locations considered in this study.

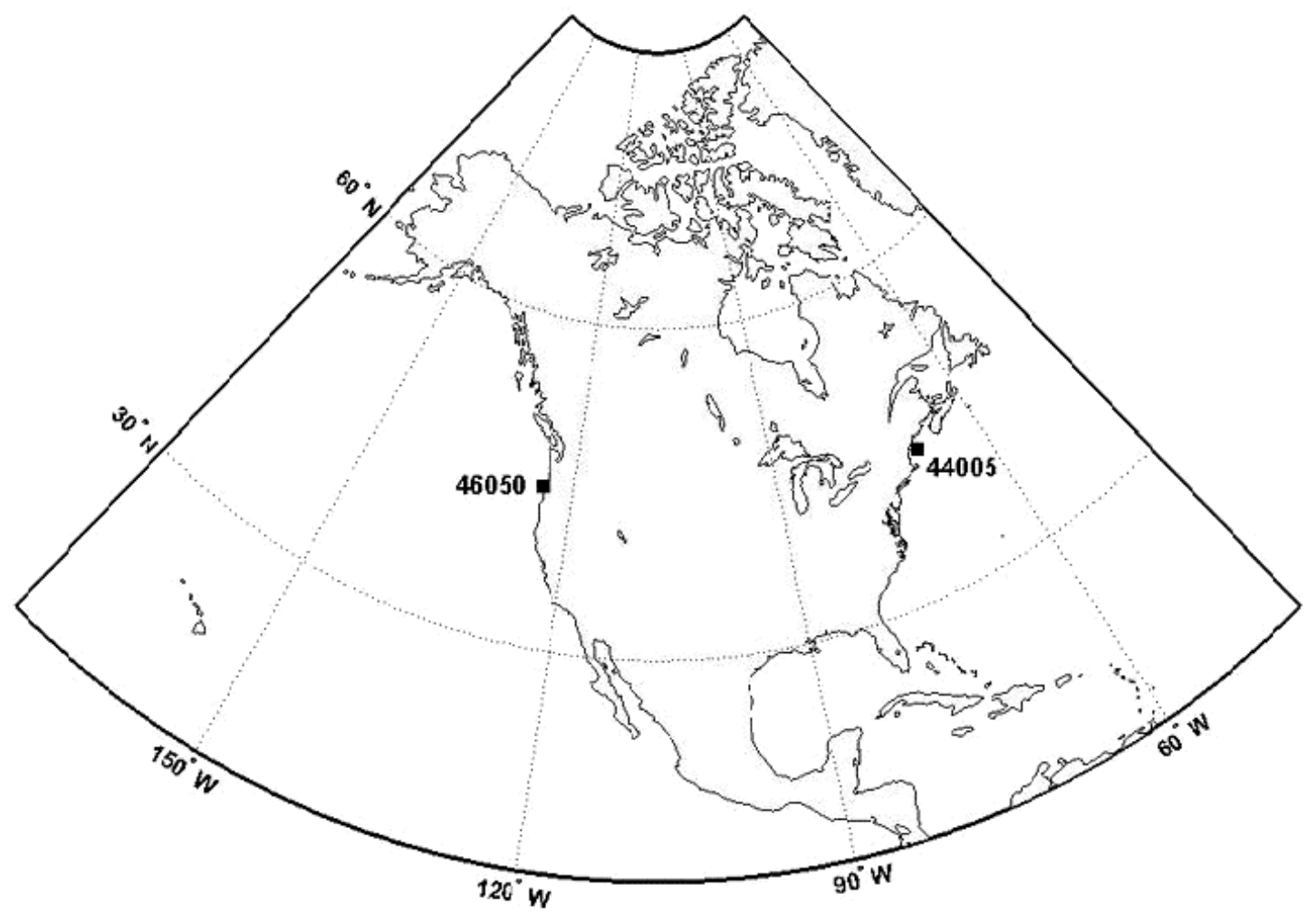

Fig. 1: Selected NOAA-National Data Buoy Centre Station locations

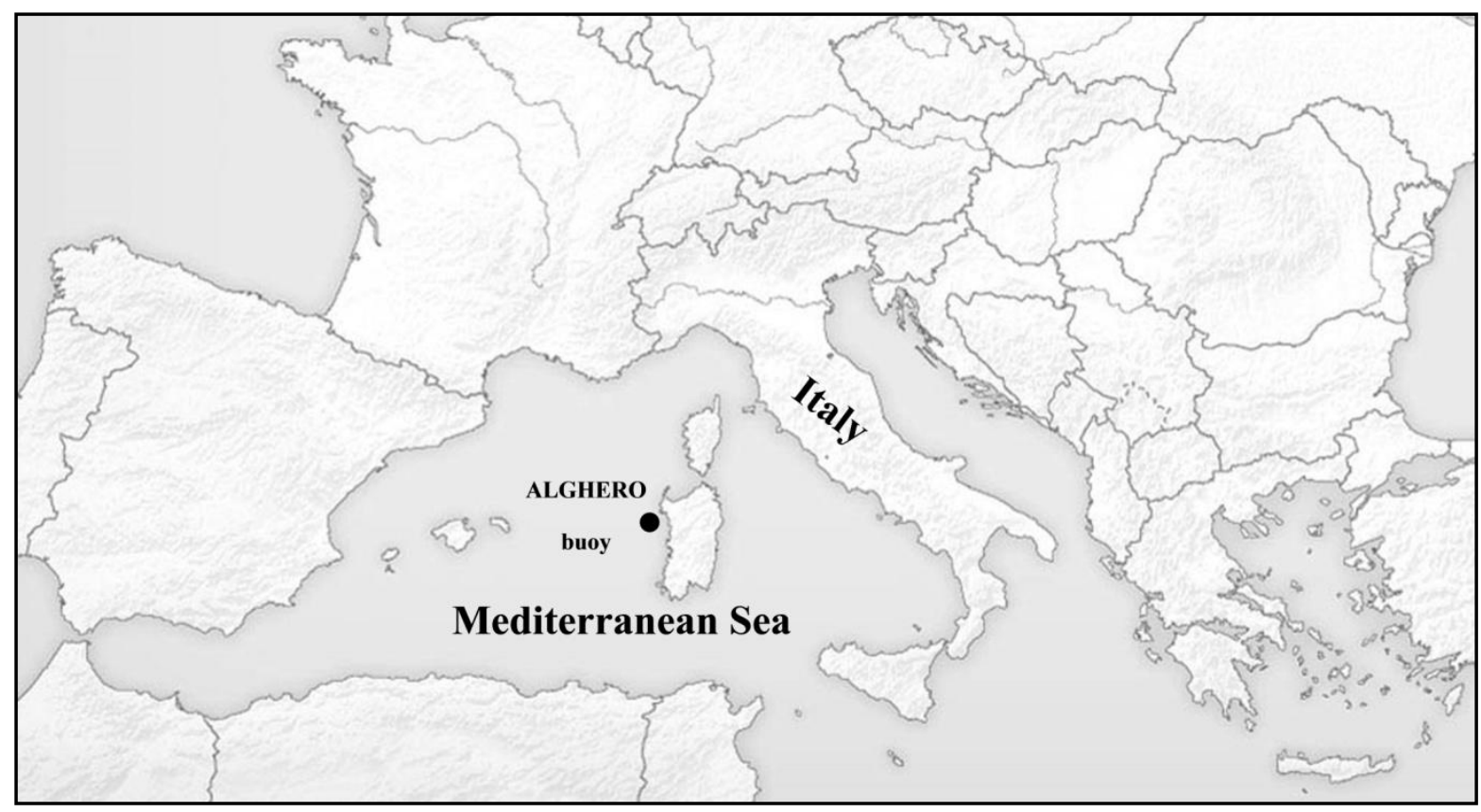

Fig. 2: Location of Alghero buoy in Mediterranean Sea 


\section{GEV DISTRIBUTION MODEL ANALYSIS}
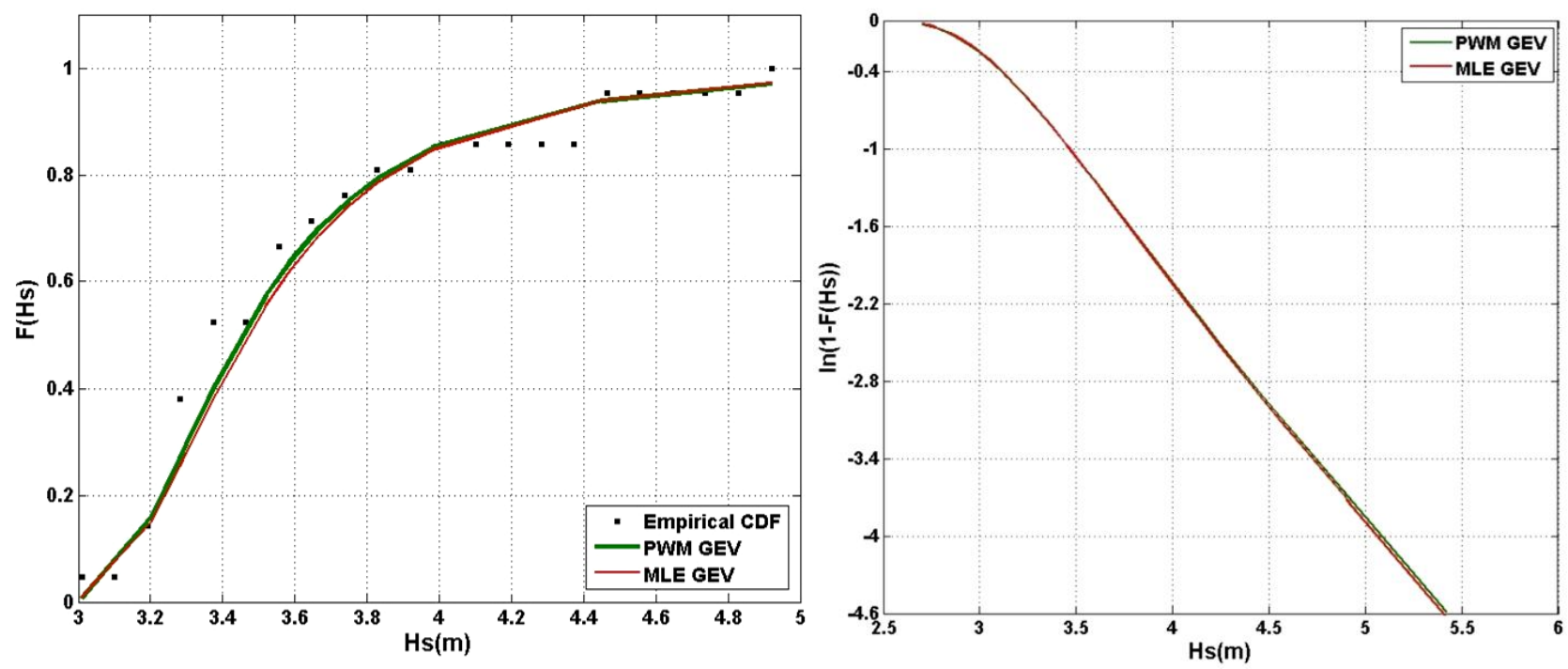

Fig. 3(a): Comparison of GEV model CDF to the empirical CDF for ERA IN-1

(b): Variation of tail GEV model CDF in logarithmic coordinates for ERA IN-1
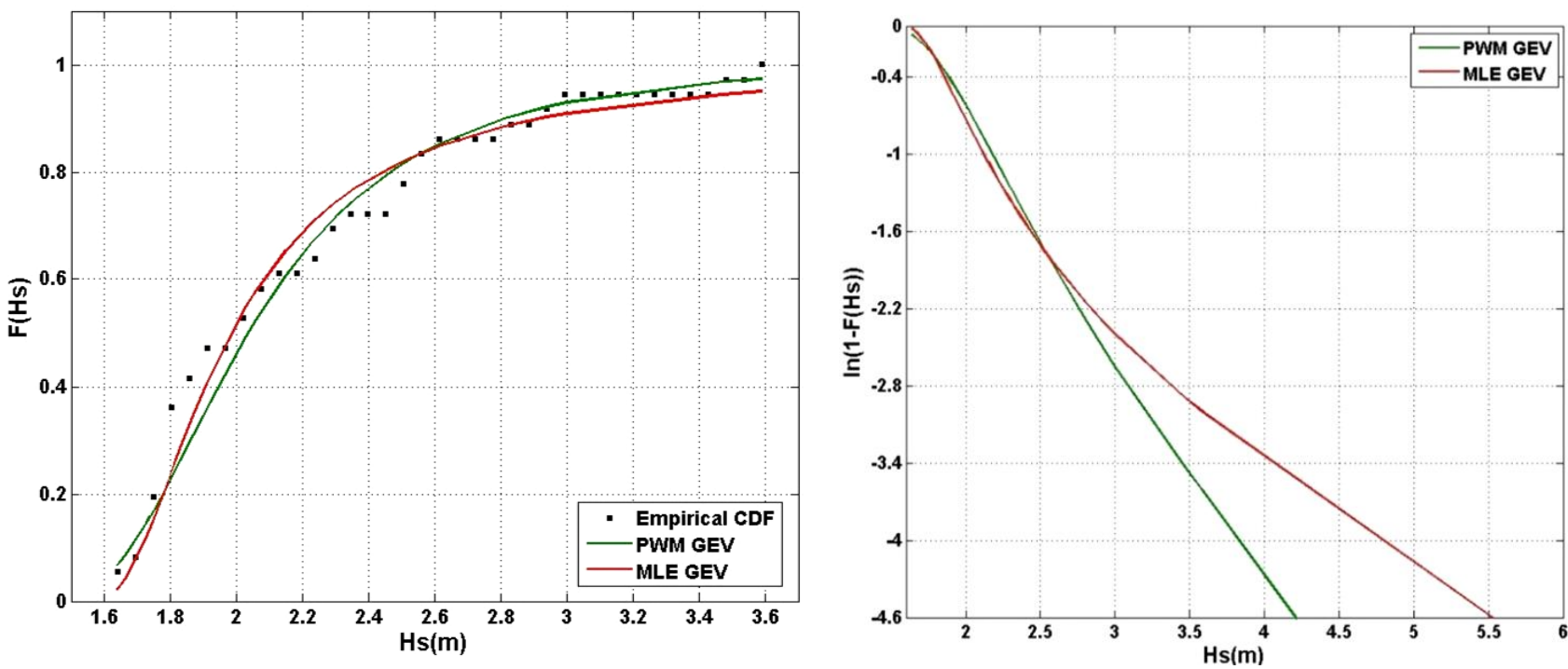

Fig. 4(a) : Comparison of GEV model CDF to the empirical CDF for ERA IN-2

(b) : Variation of tail GEV model CDF in logarithmic coordinates for ERA IN-2 

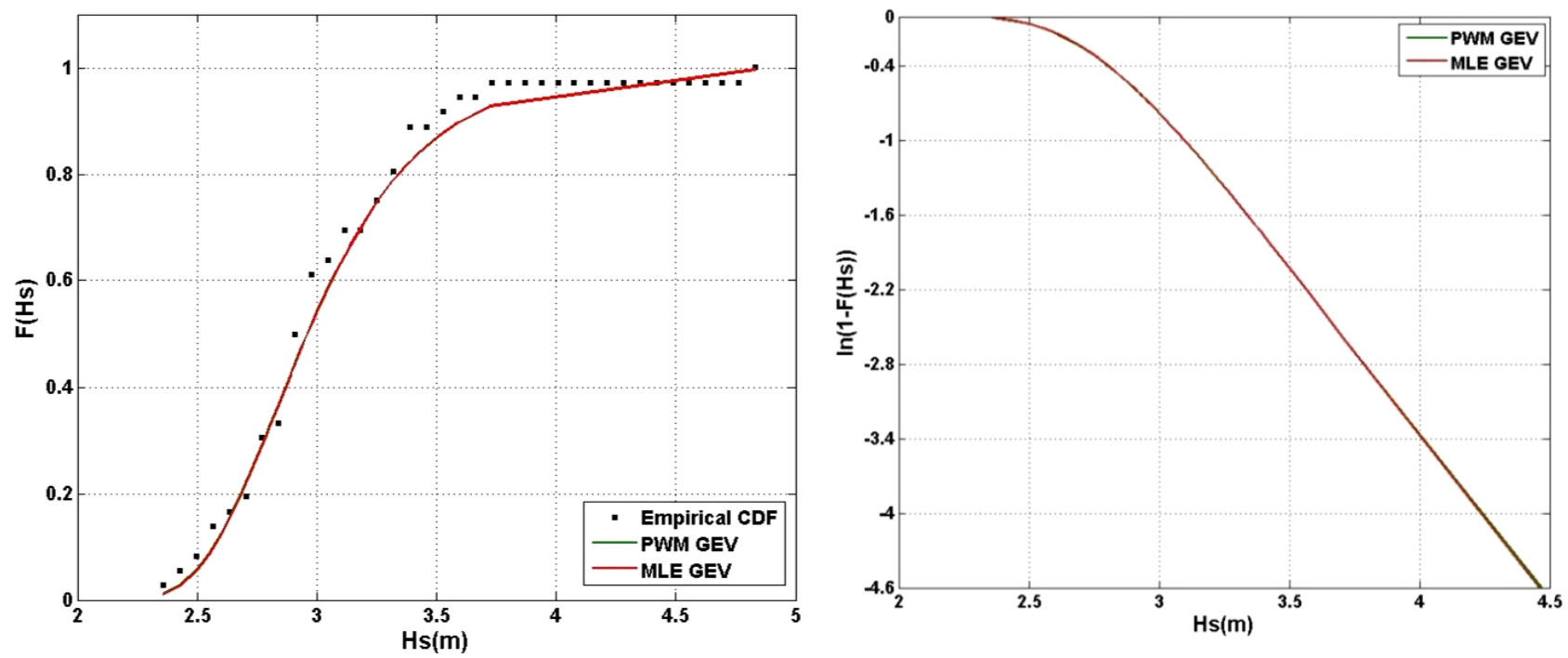

Fig. 5 (a) : Comparison of GEV model CDF to the empirical CDF for ERA IN-3

(b): Variation of tail GEV model CDF in logarithmic coordinates for ERA IN-3
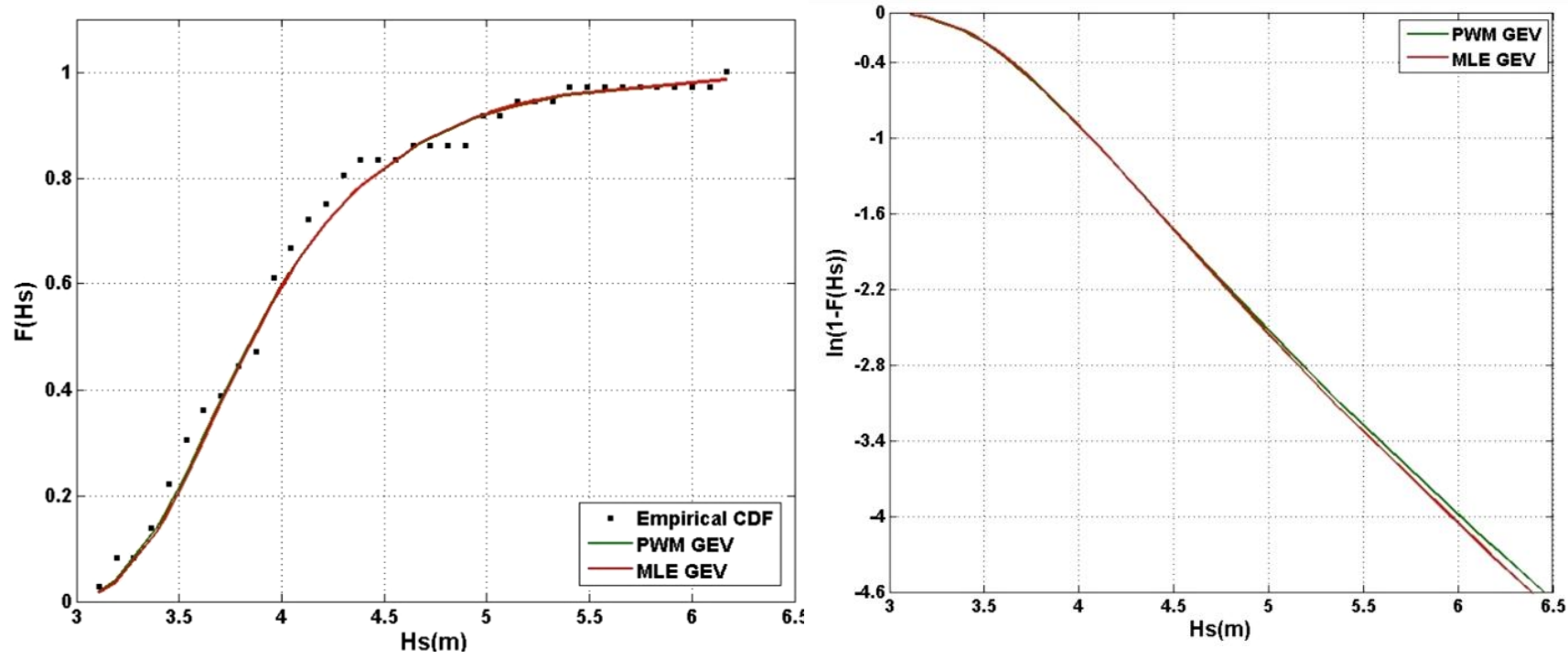

Fig. 6(a): Comparison of GEV model CDF to the empirical CDF for ERA IN-4

(b): Variation of tail GEV model CDF in logarithmic coordinates for ERA IN-4 

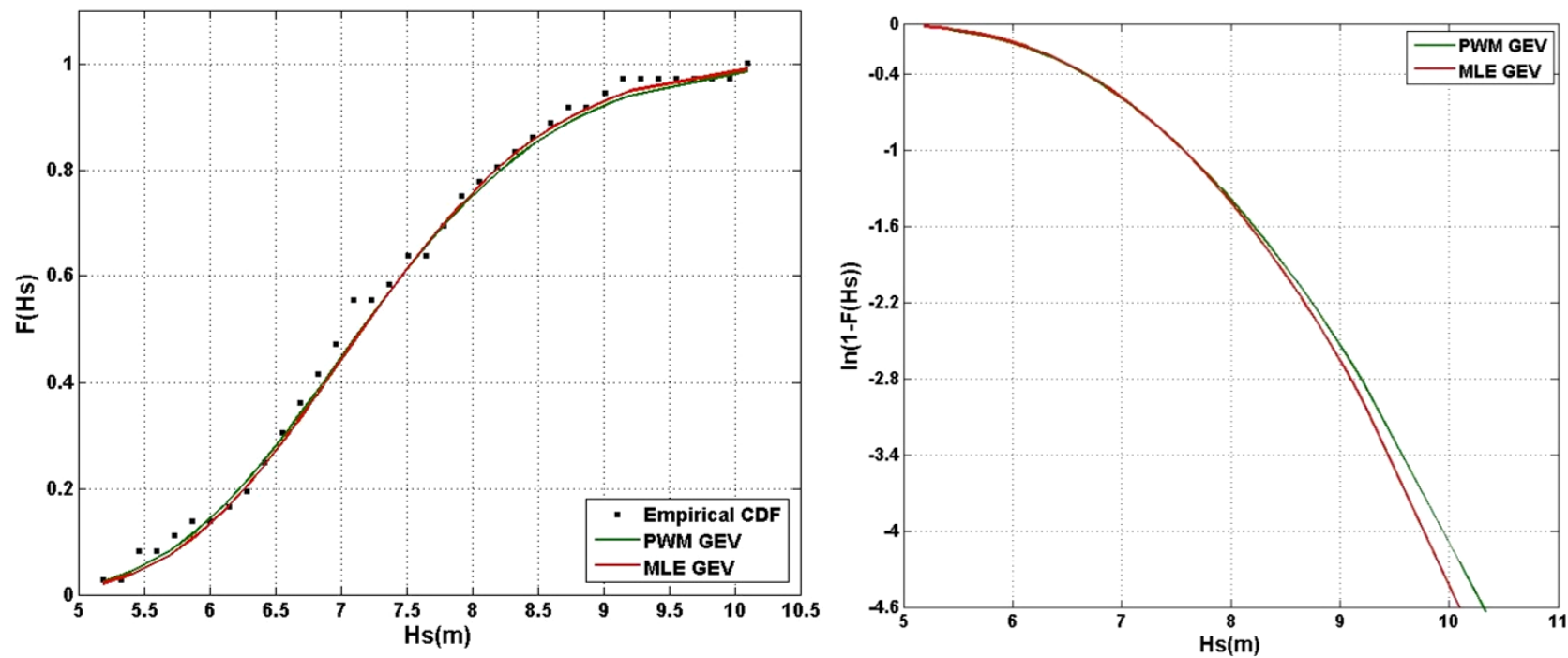

Fig. 7(a): Comparison of GEV model CDF to the empirical CDF for NOAA 44005

(b): Variation of tail GEV model CDF in logarithmic coordinates for NOAA 44005
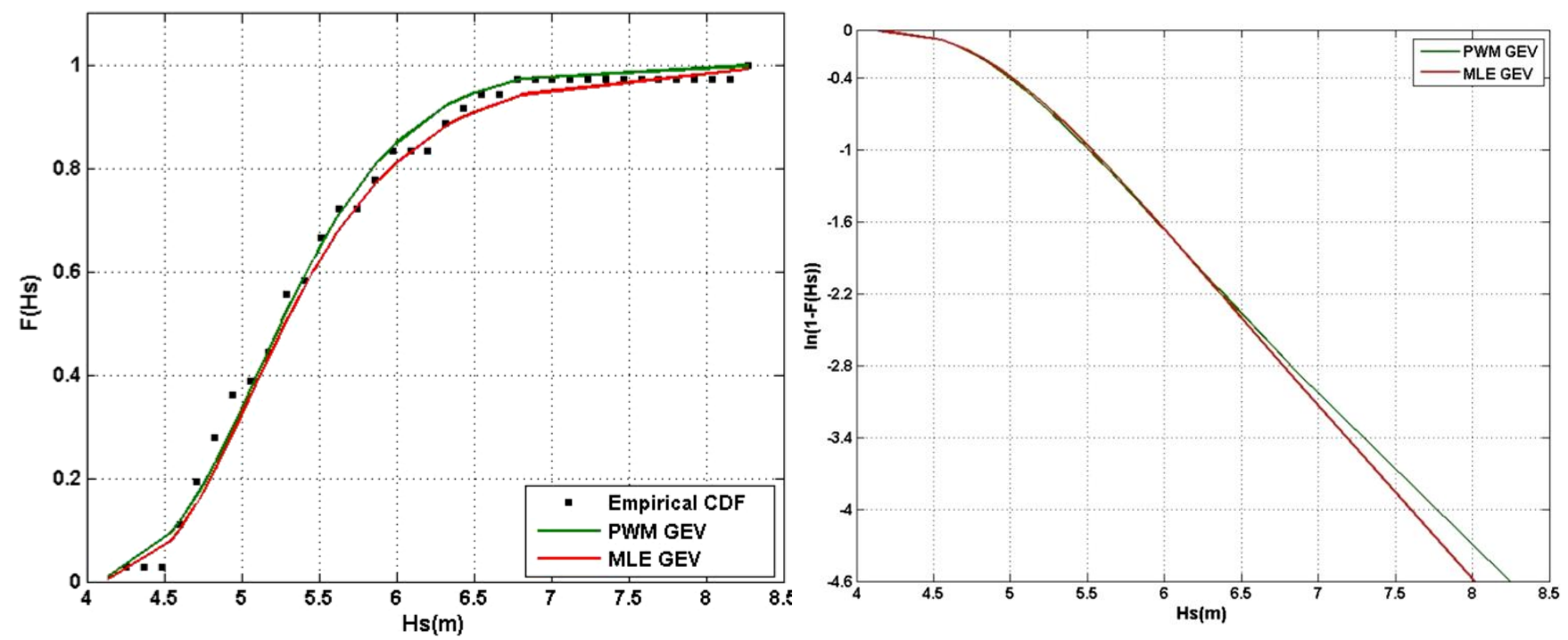

Fig. 8(a): Comparison of GEV model CDF to the empirical CDF for ERA 44005

(b): Variation of tail GEV model CDF in logarithmic coordinates for ERA 44005 

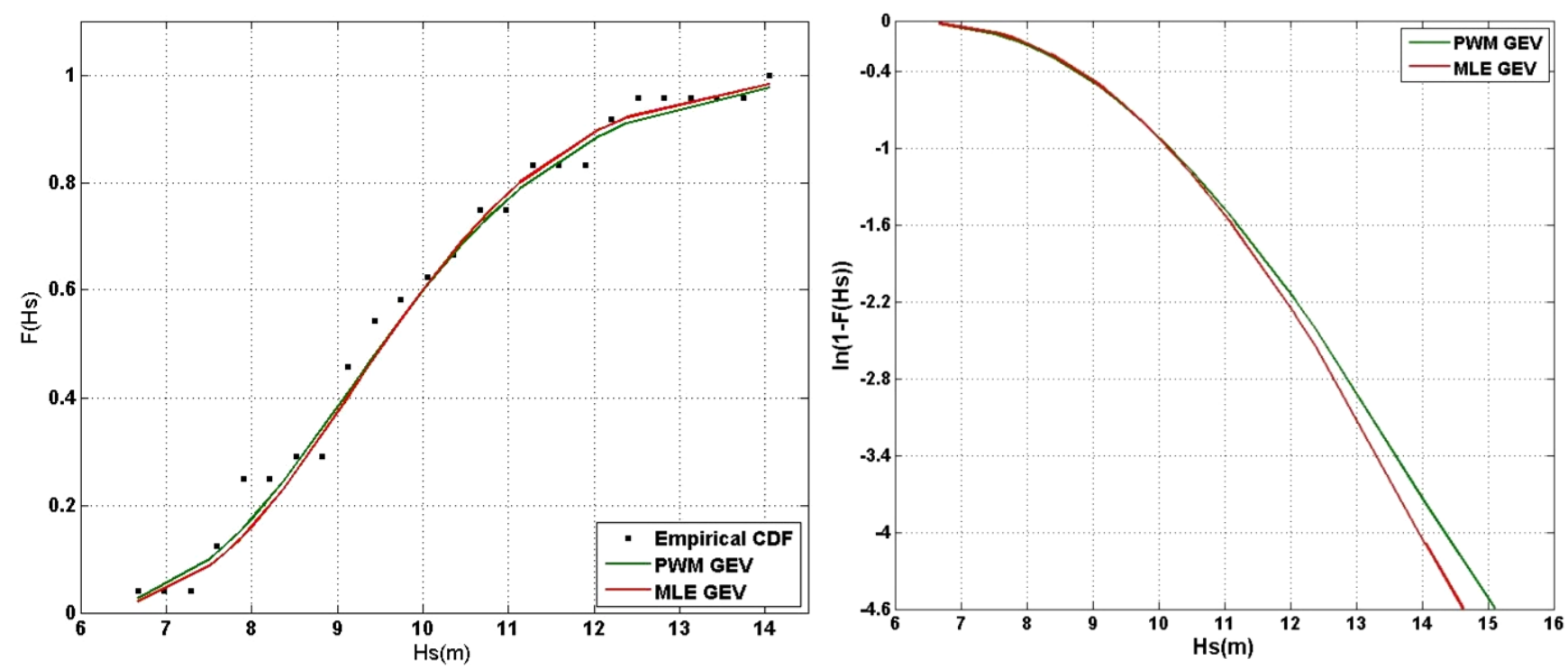

Fig. 9(a): Comparison of GEV model CDF to the empirical CDF for NOAA 46050

(b): Variation of tail GEV model CDF in logarithmic coordinates for NOAA 46050
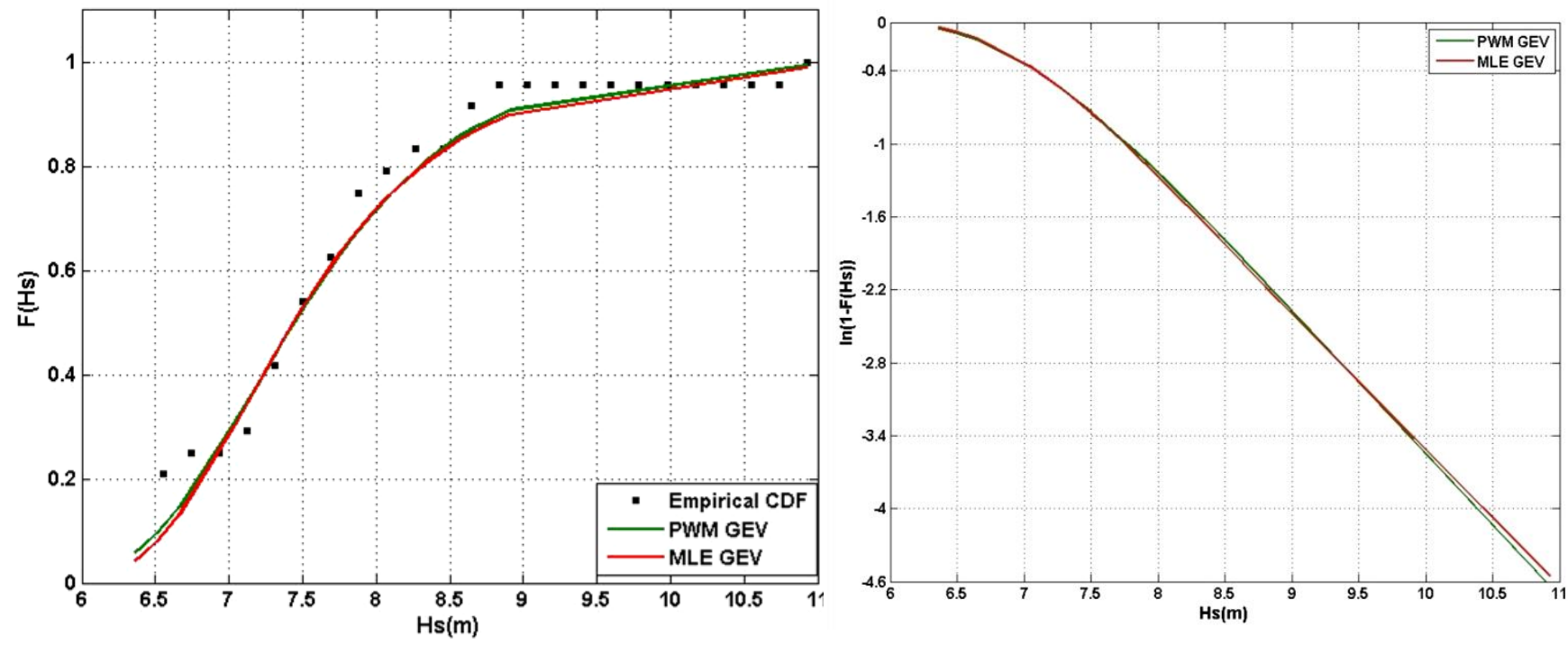

Fig. 10(a): Comparison of GEV model CDF to the empirical CDF for ERA 46050

(b): Variation of tail GEV model CDF in logarithmic coordinates for ERA 46050 

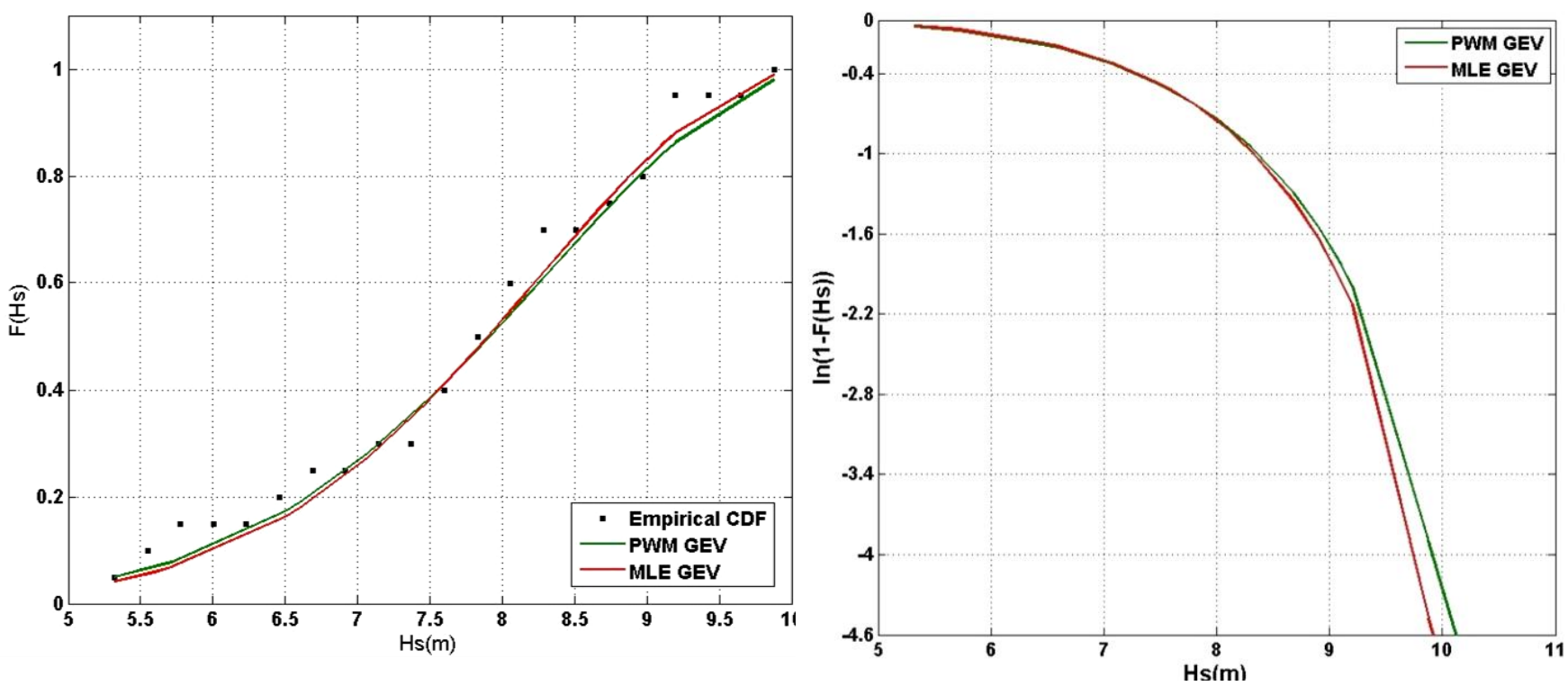

Fig. 11(a): Comparison of GEV model CDF to the empirical CDF for RON Alghero

(b) : Variation of tail GEV model CDF in logarithmic coordinates for RON Alghero
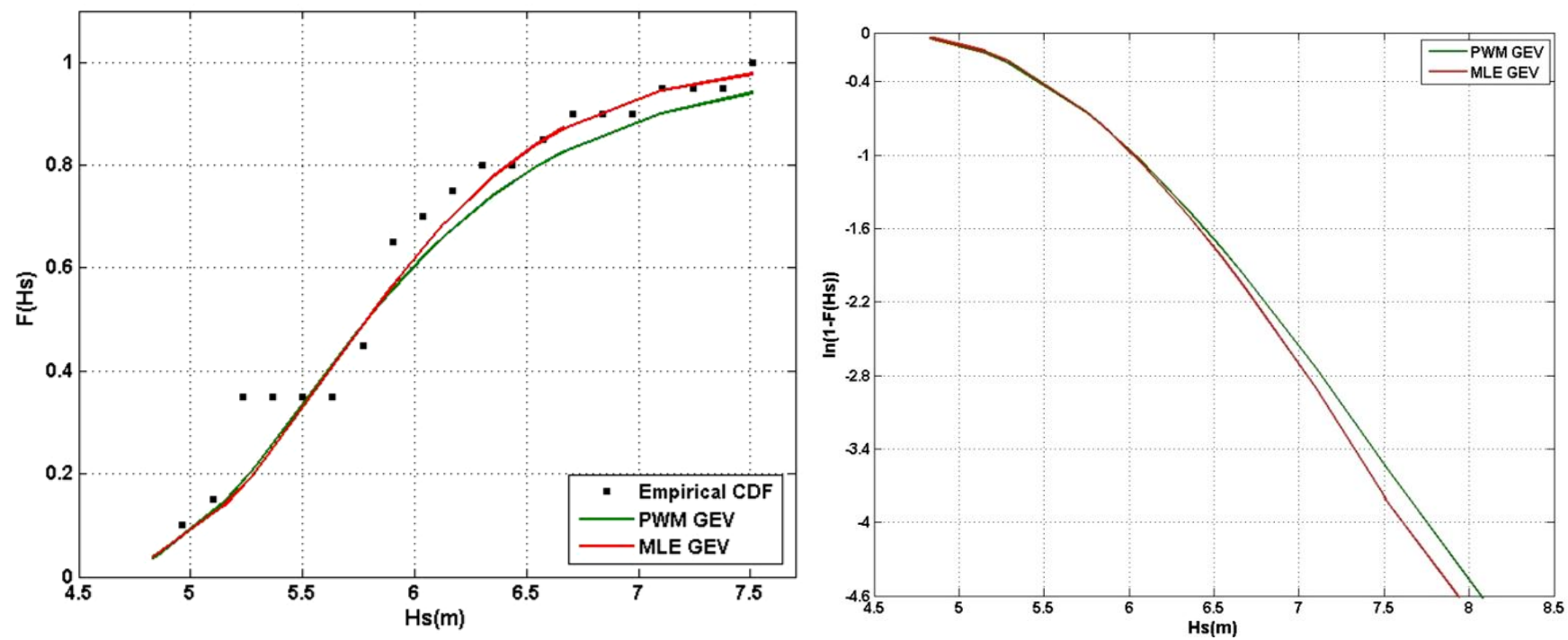

Fig. 12(a): Comparison of GEV model CDF to the empirical CDF for ERA Alghero

(b): Variation of tail GEV model CDF in logarithmic coordinates for ERA Alghero 


\section{GENERALISED PARETO DISTRIBUTION ANALYSIS}

… 95\% Confidence Interval — Fitted PWM GPD model DDDD POT sampled data

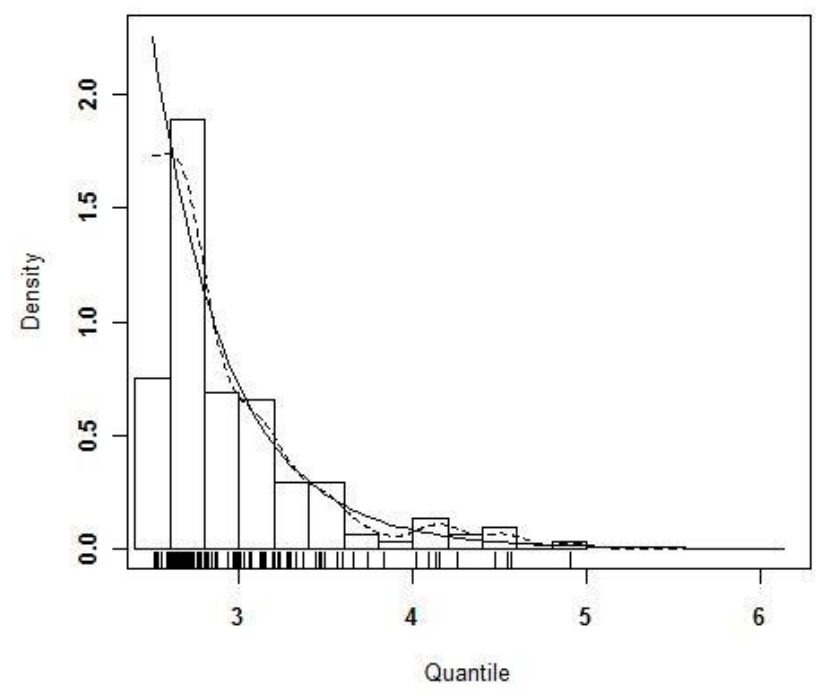

(a)

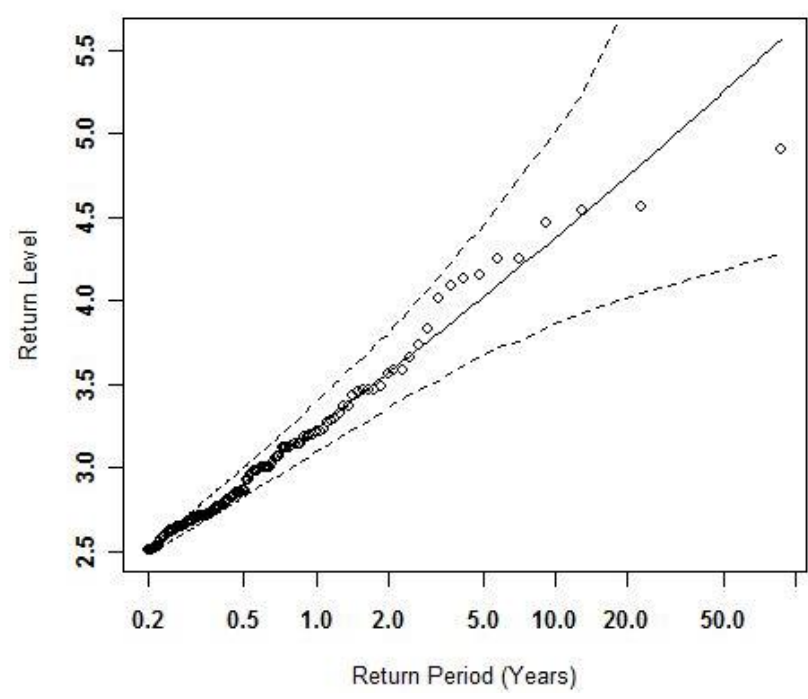

(b)

Fig. 13 :(a) Density plot of GPD model for ERA IN-1 POT data from PWM method

(b) Return level plot of GPD model for ERA IN-1 POT data from PWM method

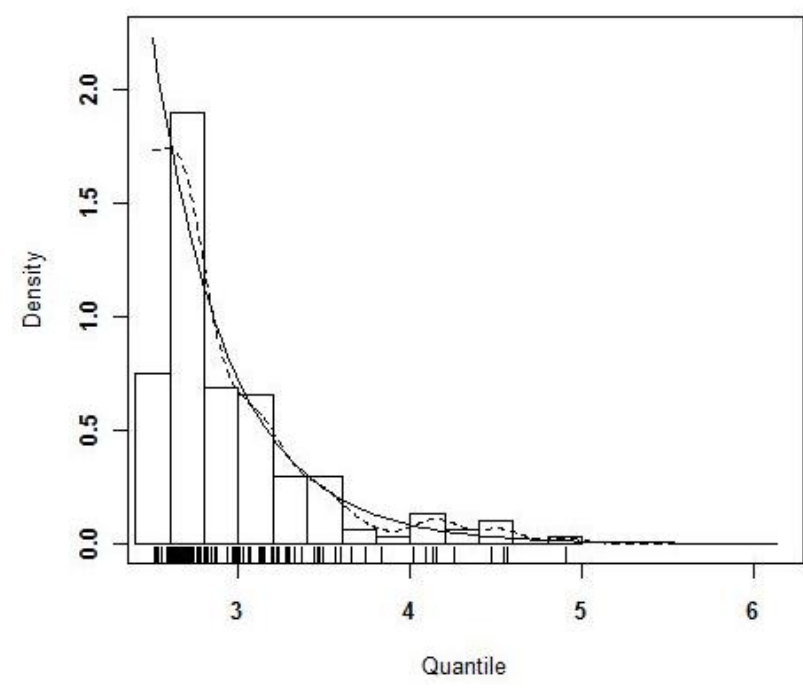

(a)

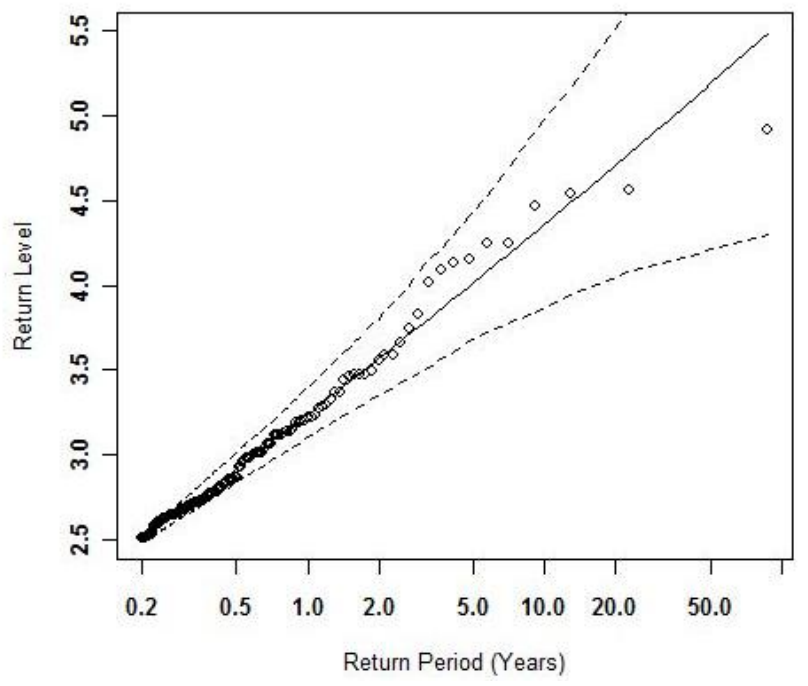

(b)

Fig. 14 :(a) Density plot of GPD model for ERA IN-1 POT data from MLE method (b) Return level plot of GPD model for ERA IN-1 POT data from MLE method 


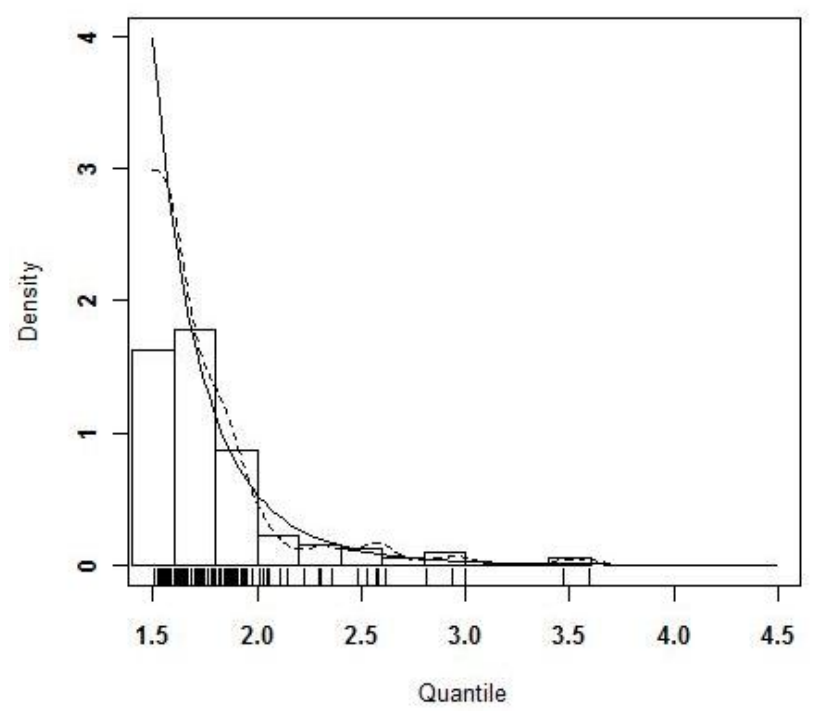

(a)

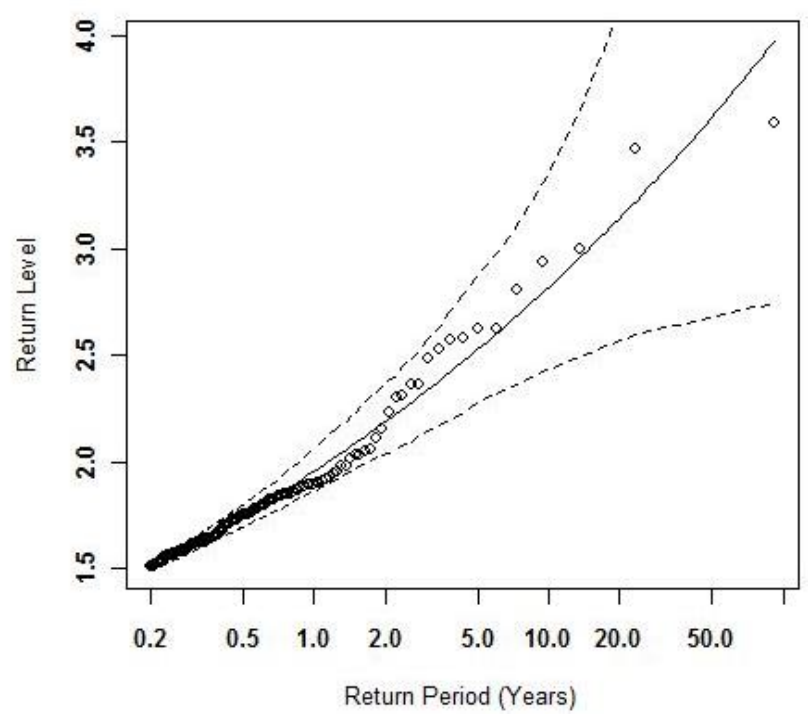

(b)

Fig. 15 :(a) Density plot of GPD model for ERA IN-2 POT data from PWM method

(b) Return level plot of GPD model for ERA IN-2 POT data from PWM method

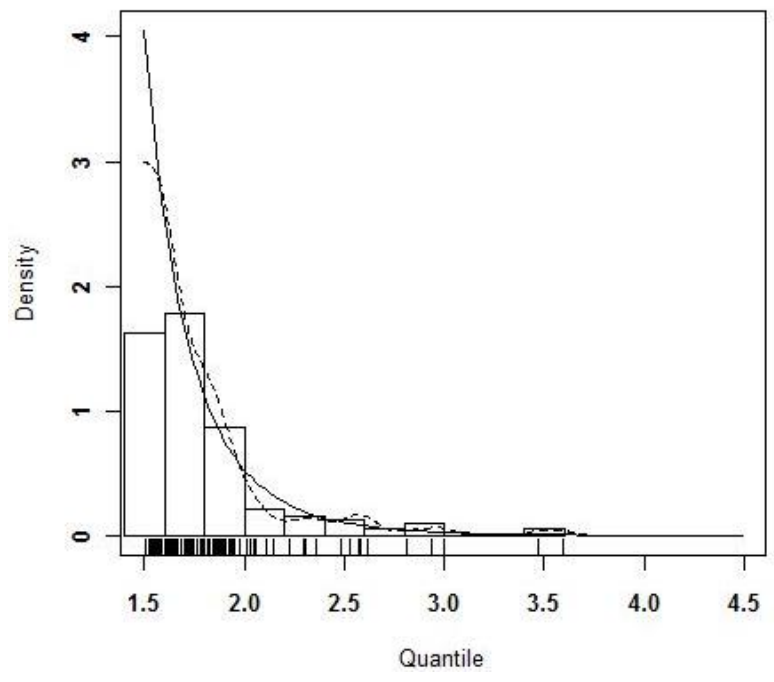

(a)

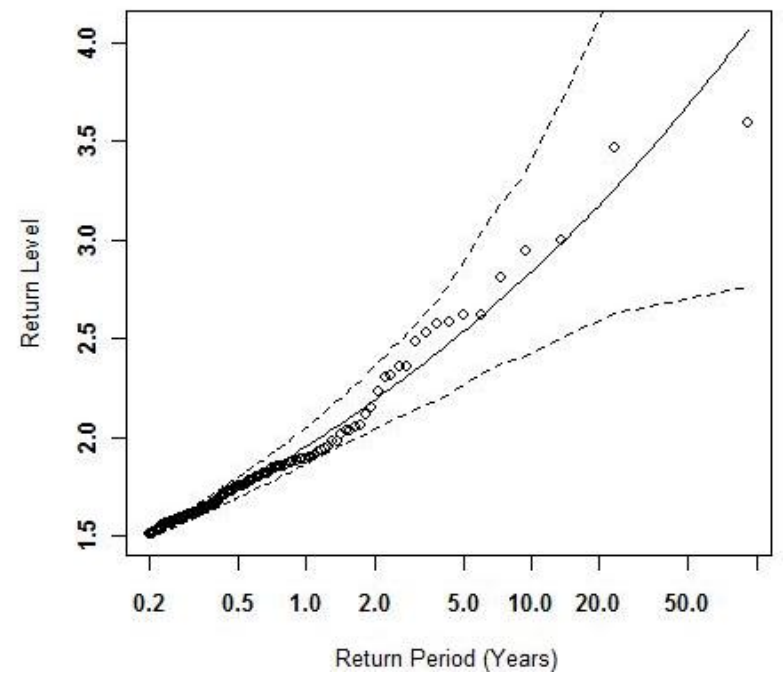

(b)

Fig. 16 :(a) Density plot of GPD model for ERA IN-2 POT data from MLE method

(b) Return level plot of GPD model for ERA IN-2 POT data from MLE method 


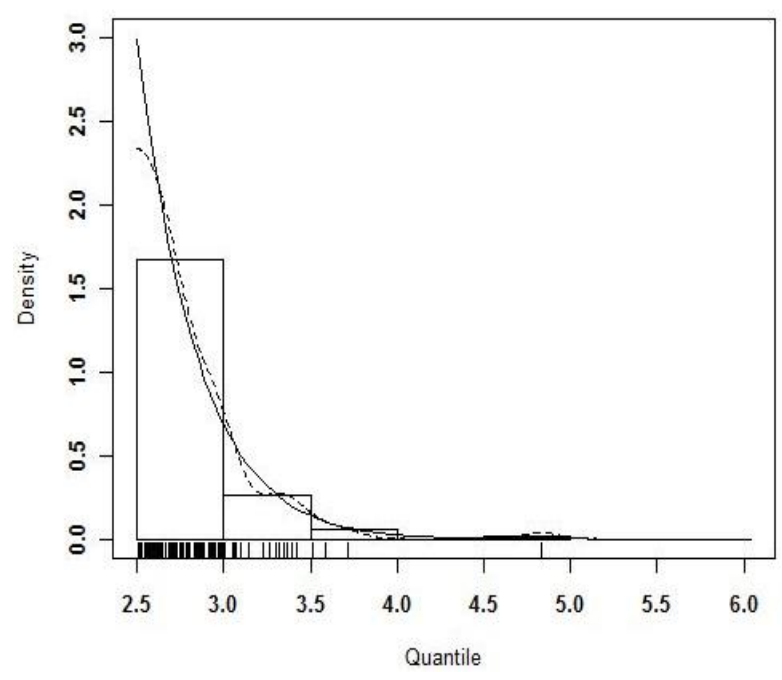

(a)

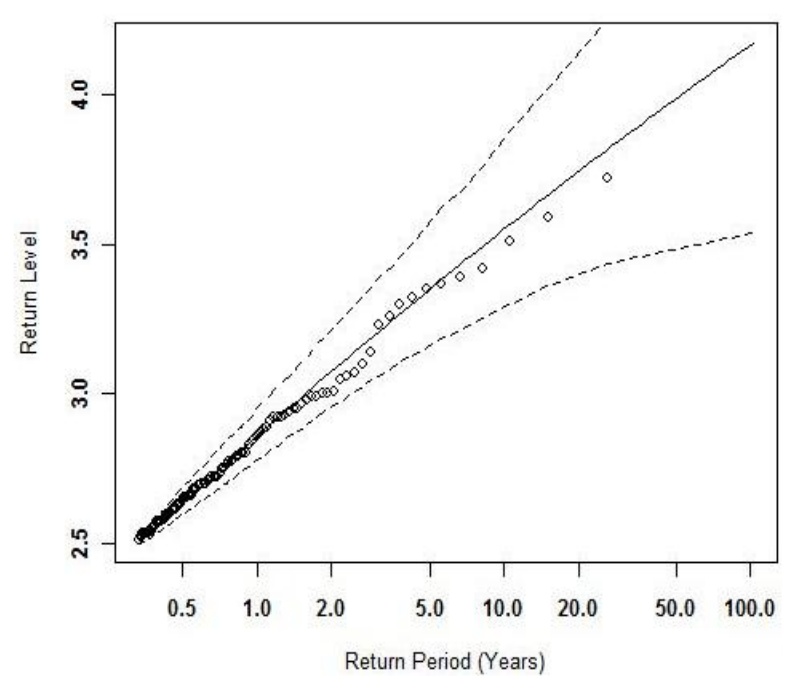

(b)

Fig. 17 :(a) Density plot of GPD model for ERA IN-3 POT data from PWM method

(b) Return level plot of GPD model for ERA IN-3 POT data from PWM method

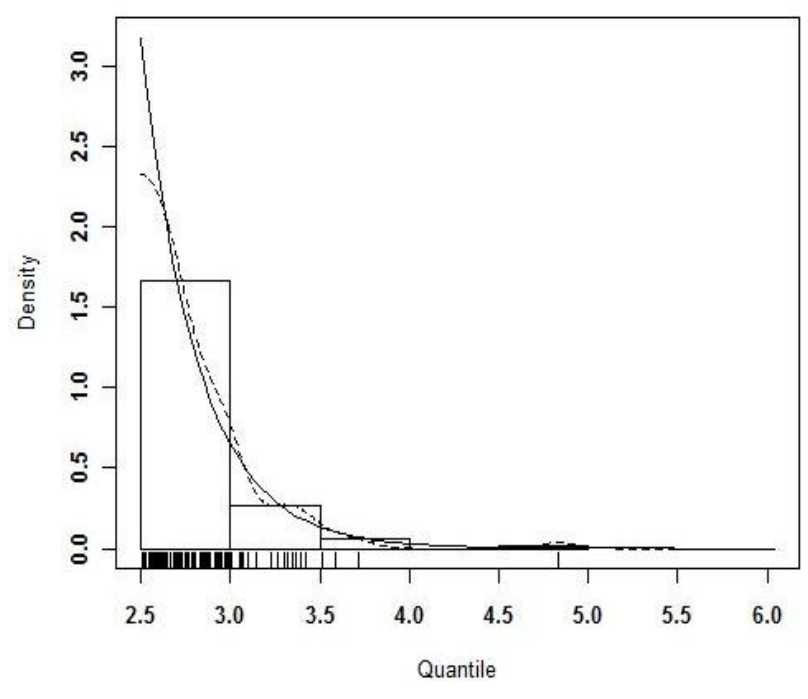

(a)

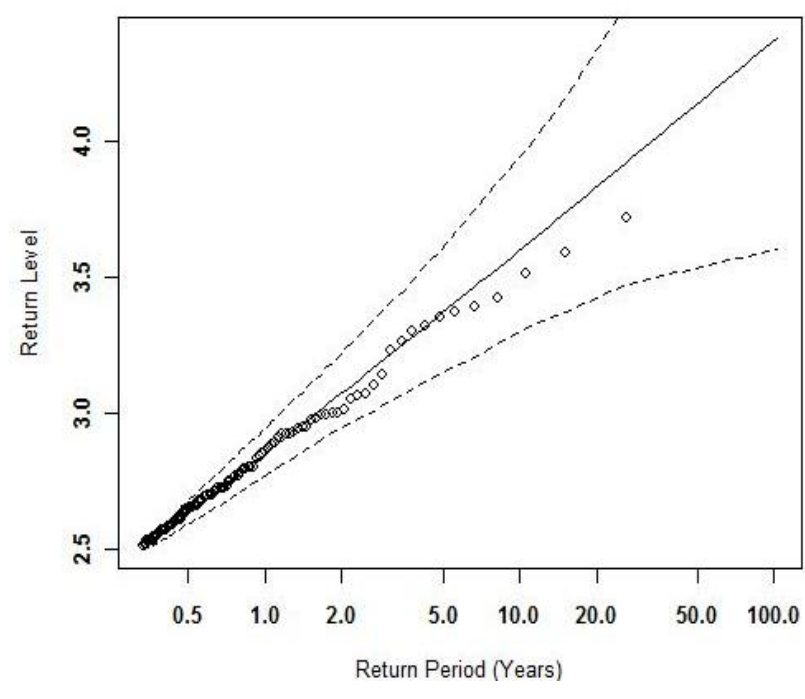

(b)

Fig. 18 :(a) Density plot of GPD model for ERA IN-3 POT data from MLE method

(b) Return level plot of GPD model for ERA IN-3 POT data from MLE method 


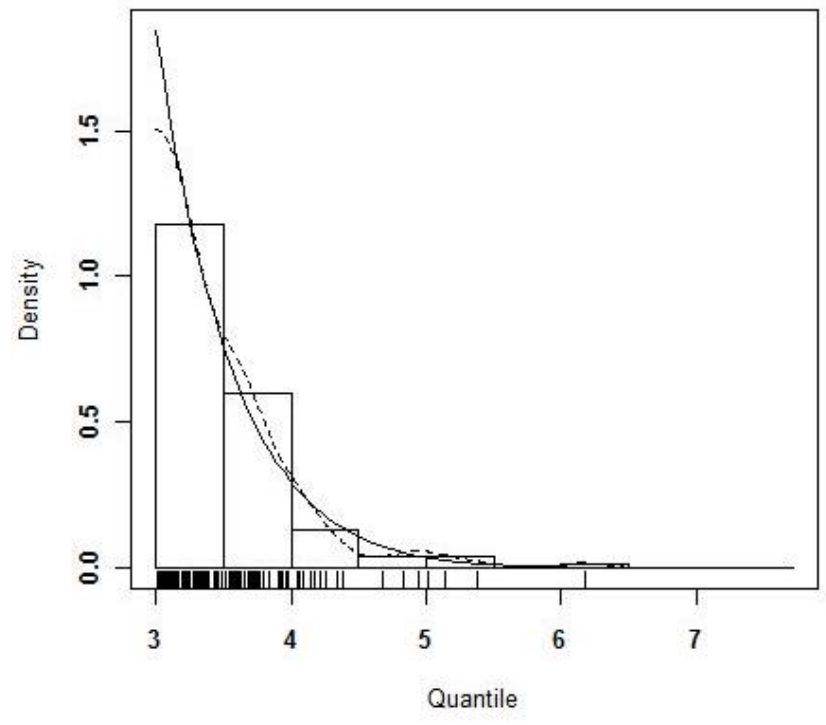

(a)

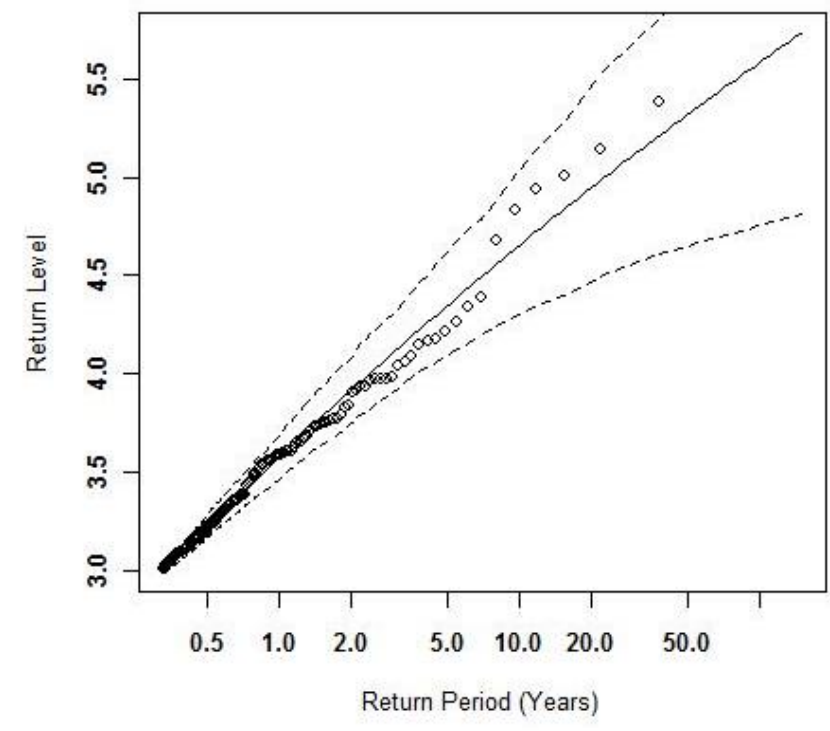

(b)

Fig. 19 : (a) Density plot of GPD model for ERA IN-4 POT data from PWM method

(b) Return level plot of GPD model for ERA IN-4 POT data from PWM method

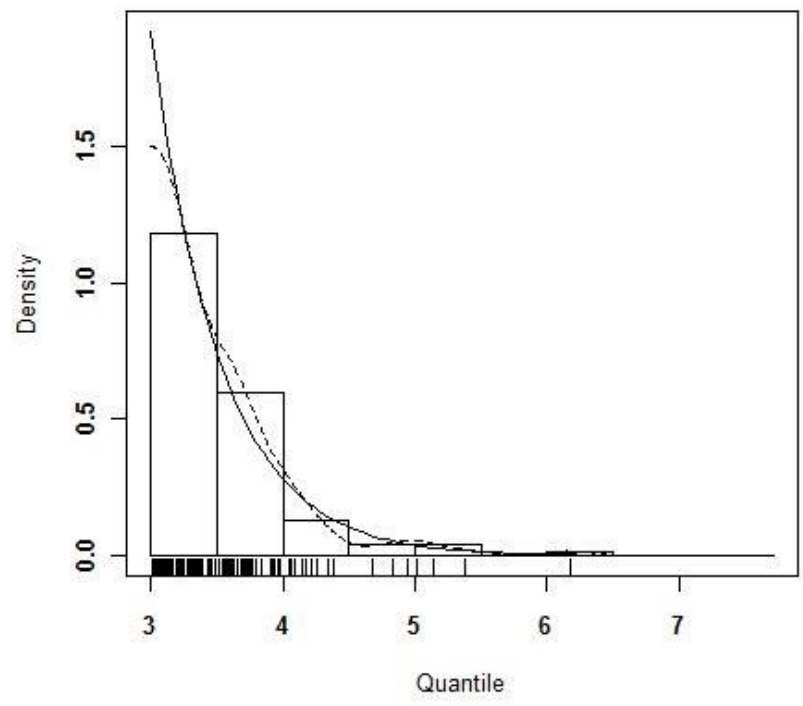

(a)

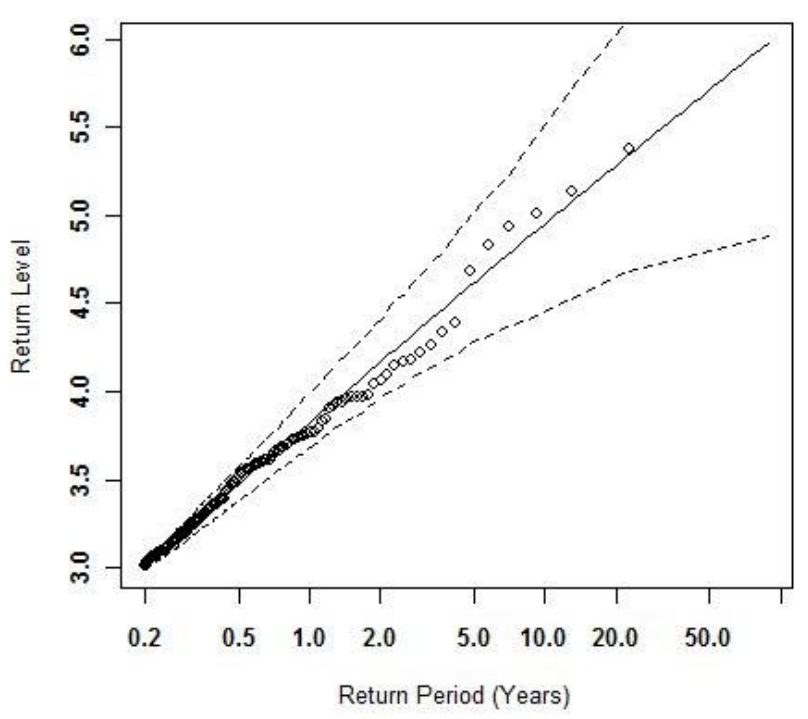

(b)

Fig. 20 :(a) Density plot of GPD model for ERA IN-4 POT data from MLE method

(b) Return level plot of GPD model for ERA IN-4 POT data from MLE method 


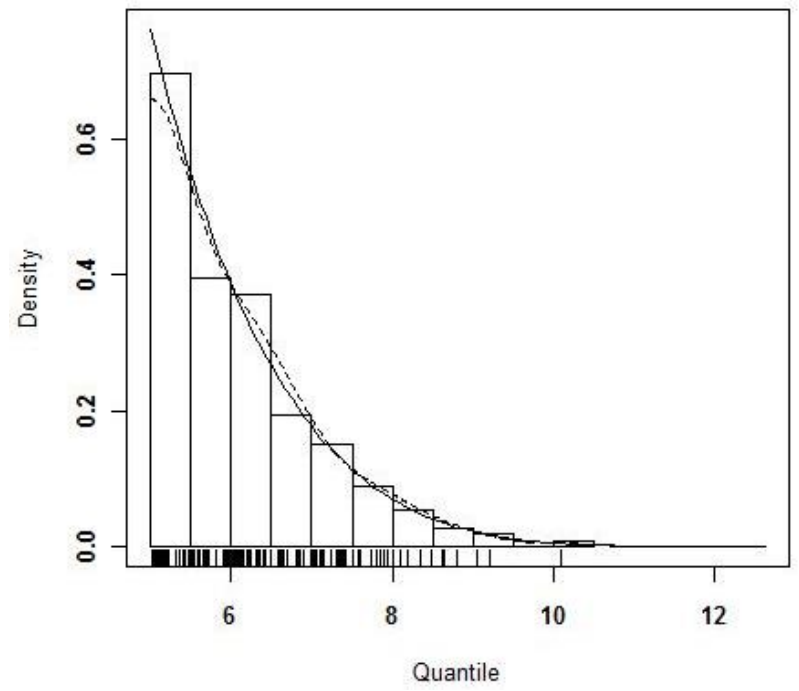

(a)

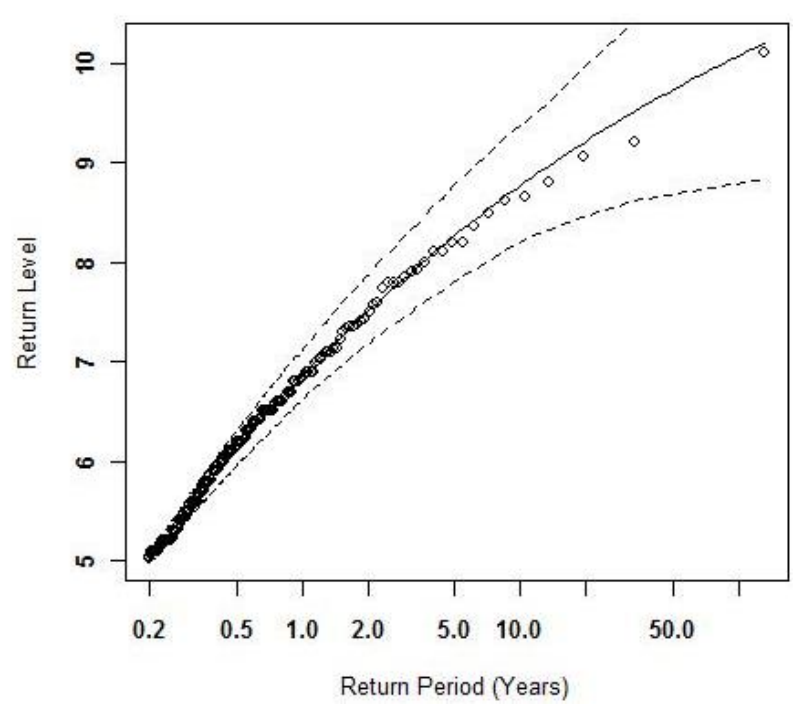

(b)

Fig. 21 : (a) Density plot of GPD model for NOAA44005 POT data from PWM method

(b) Return level plot of GPD model for NOAA44005 POT data from PWM method

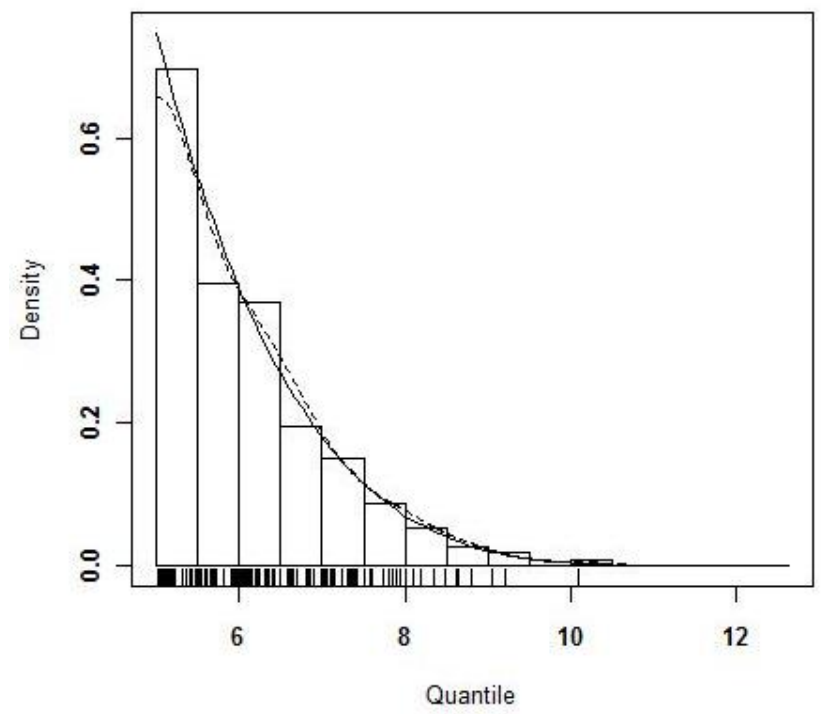

(a)

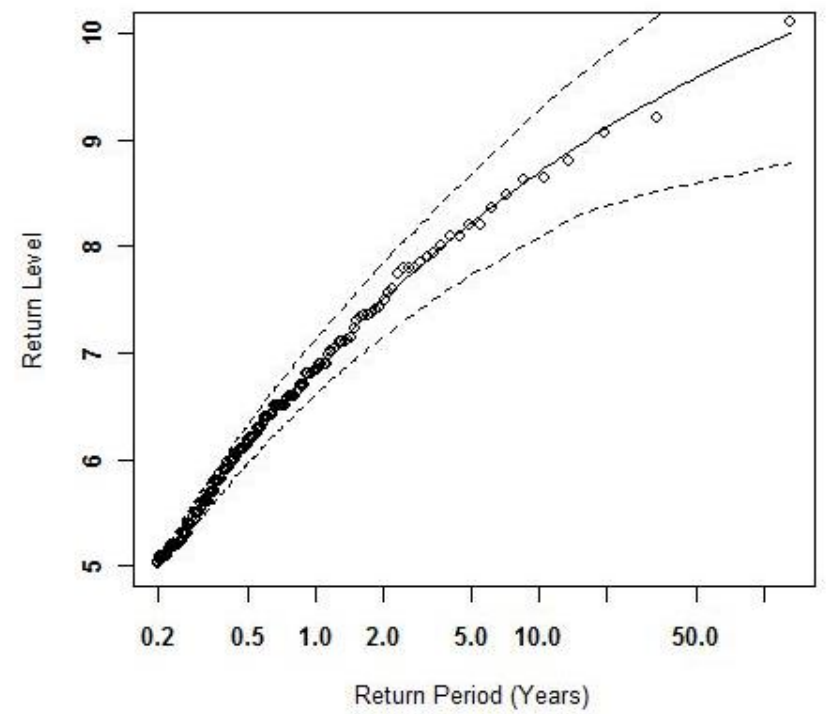

(b)

Fig. 22 : (a) Density plot of GPD model for NOAA44005 POT data from MLE method

(b) Return level plot of GPD model for NOAA44005 POT data from MLE method 


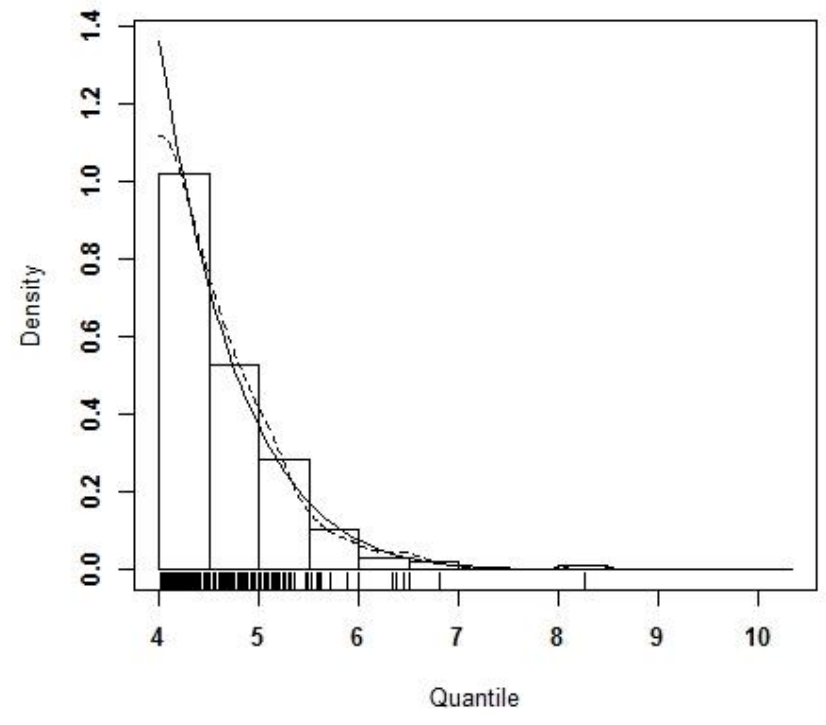

(a)

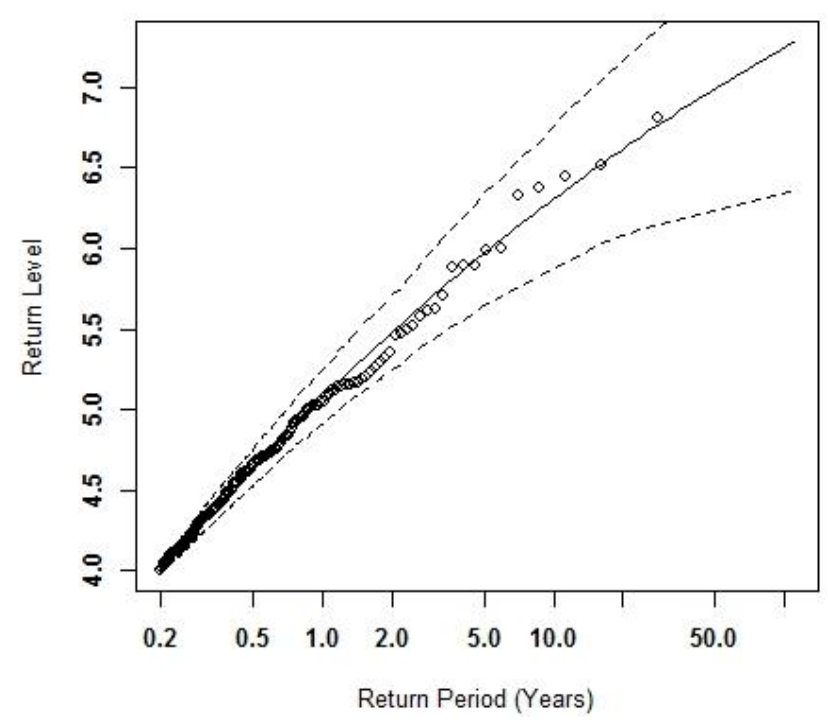

(b)

Fig. 23 : (a) Density plot of GPD model for ERA 44005 POT data from PWM method

(b) Return level plot of GPD model for ERA 44005 POT data from PWM method

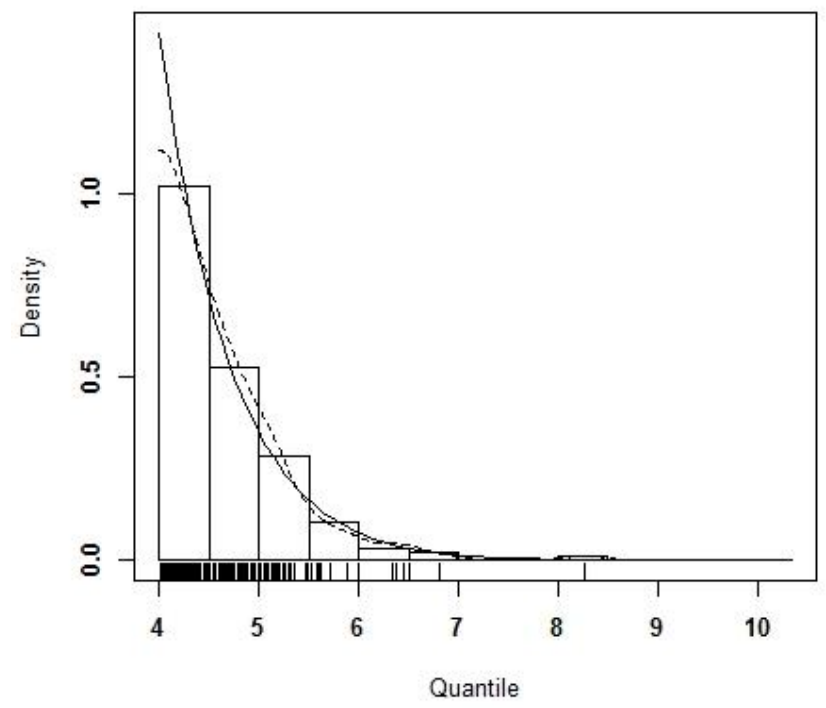

(a)

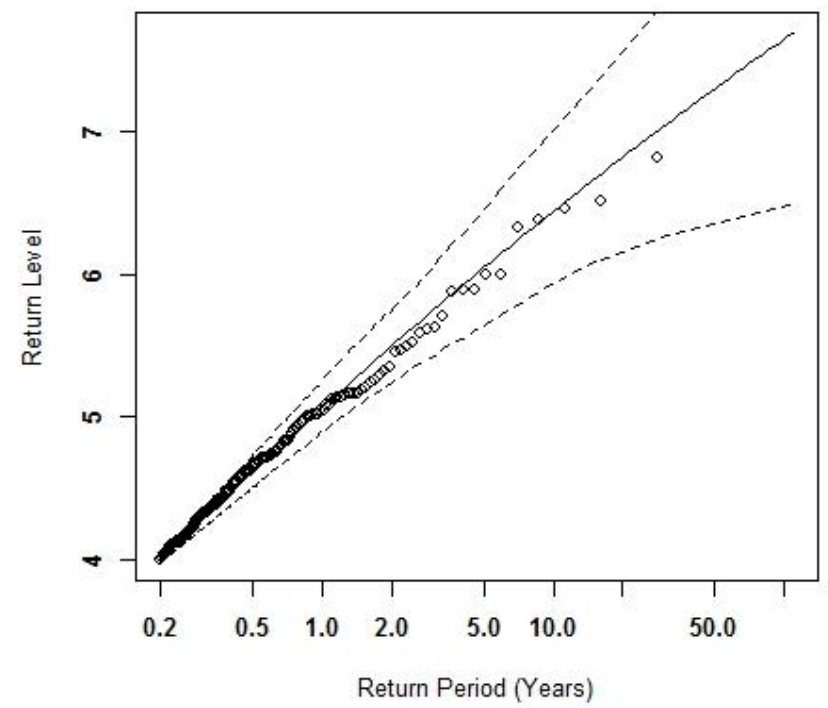

(b)

Fig. 24 : (a) Density plot of GPD model for ERA 44005 POT data from MLE method

(b) Return level plot of GPD model for ERA 44005 POT data from MLE method 


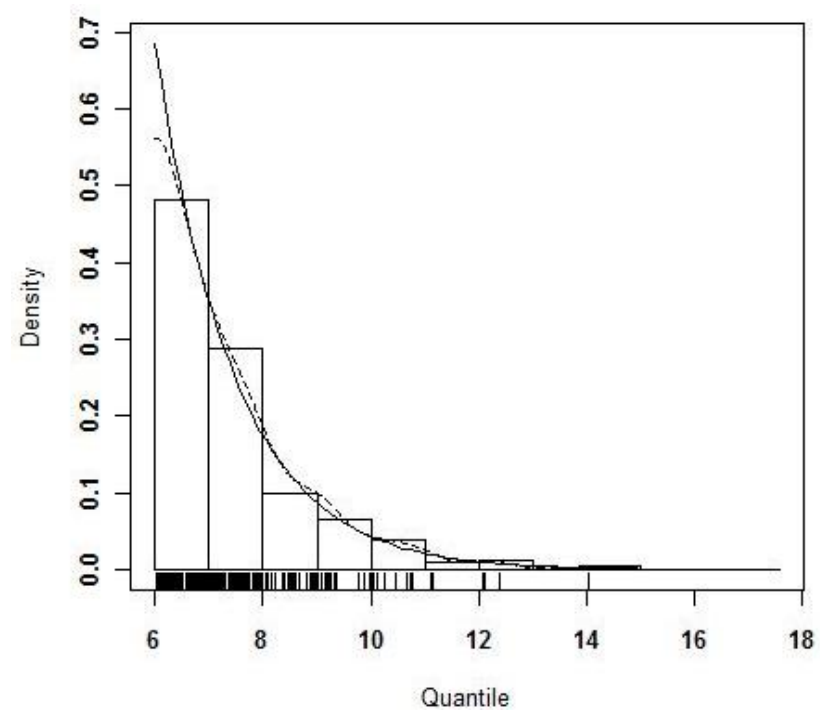

(a)

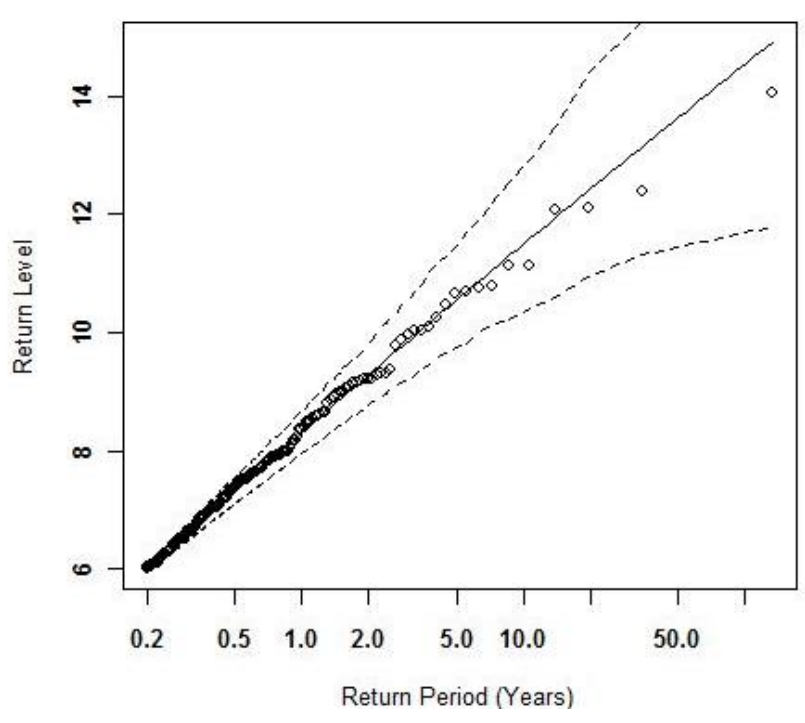

(b)

Fig. 25 :(a) Density plot of GPD model for NOAA 46050 POT data from PWM method

(b) Return level plot of GPD model for NOAA 46050 POT data from PWM method

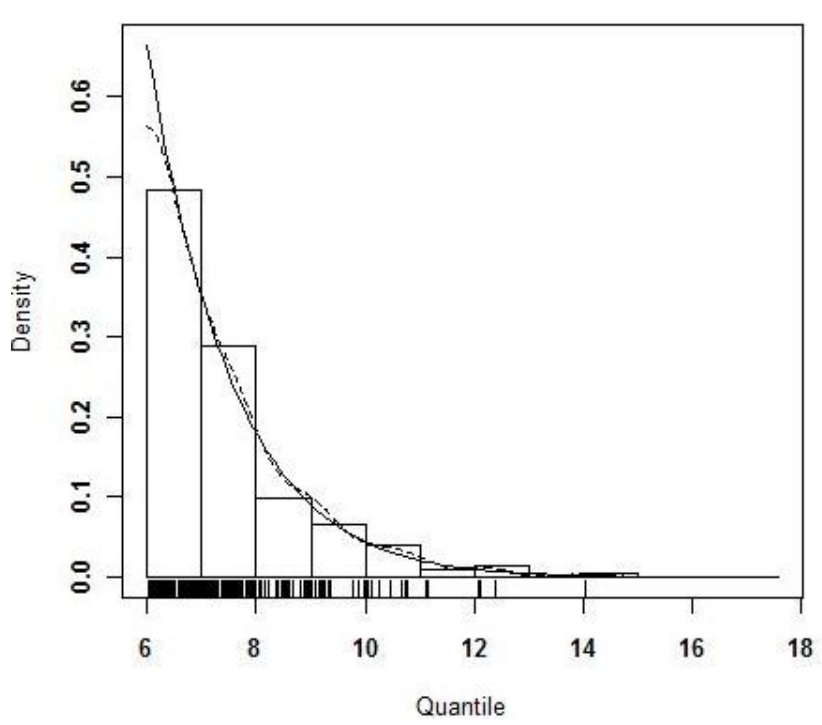

(a)

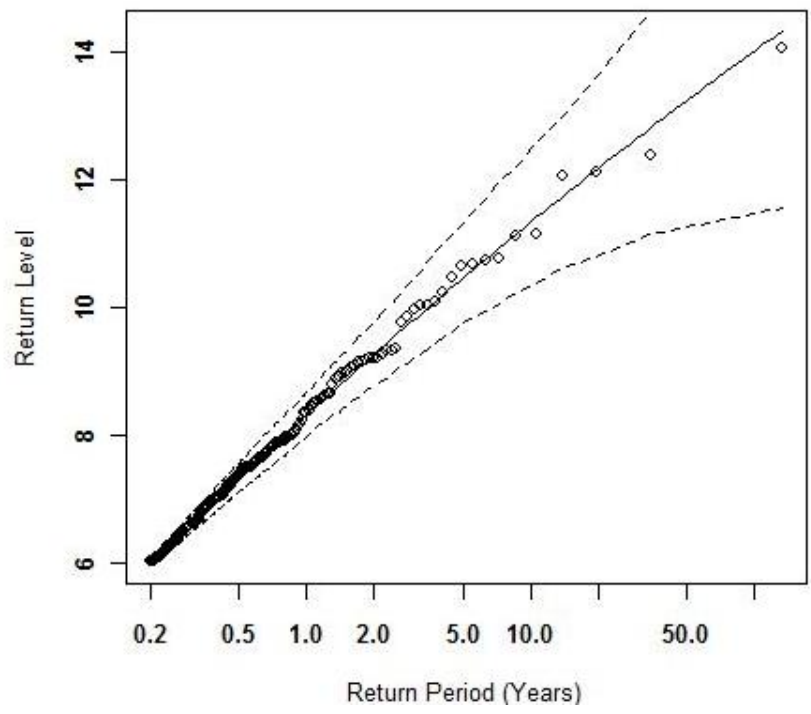

(b)

Fig. 26 :(a) Density plot of GPD model for NOAA 46050 POT data from MLE method

(b) Return level plot of GPD model for NOAA 46050 POT data from MLE method 


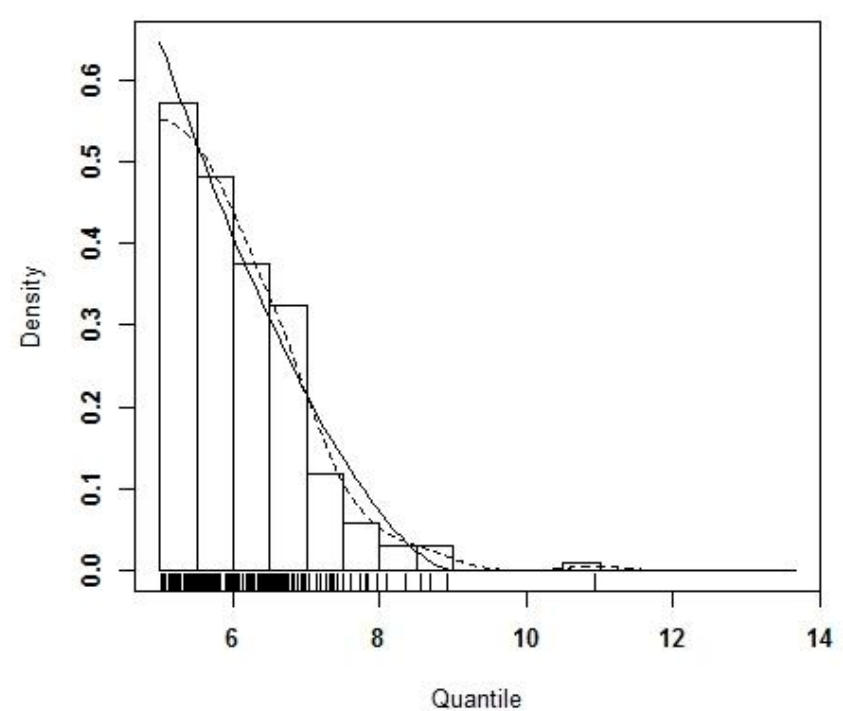

(a)

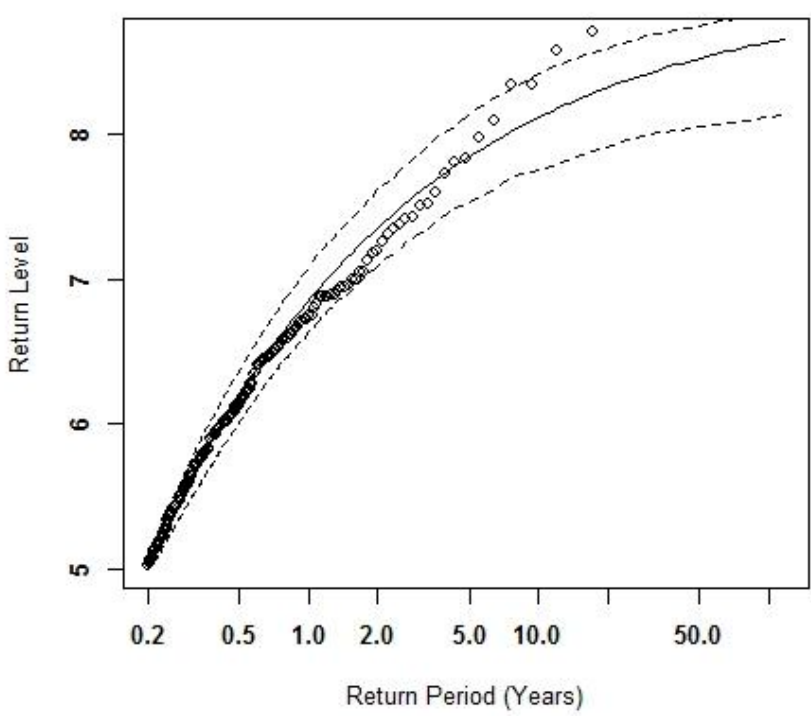

(b)

Fig. 27 :(a) Density plot of GPD model for ERA 46050 POT data from PWM method (b) Return level plot of GPD model for ERA 46050 POT data from PWM method

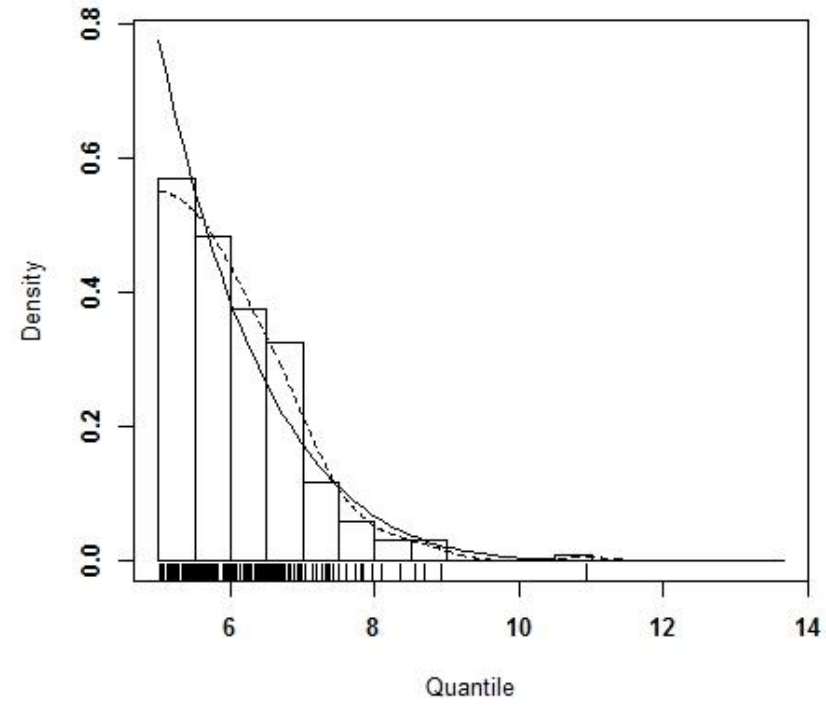

(a)

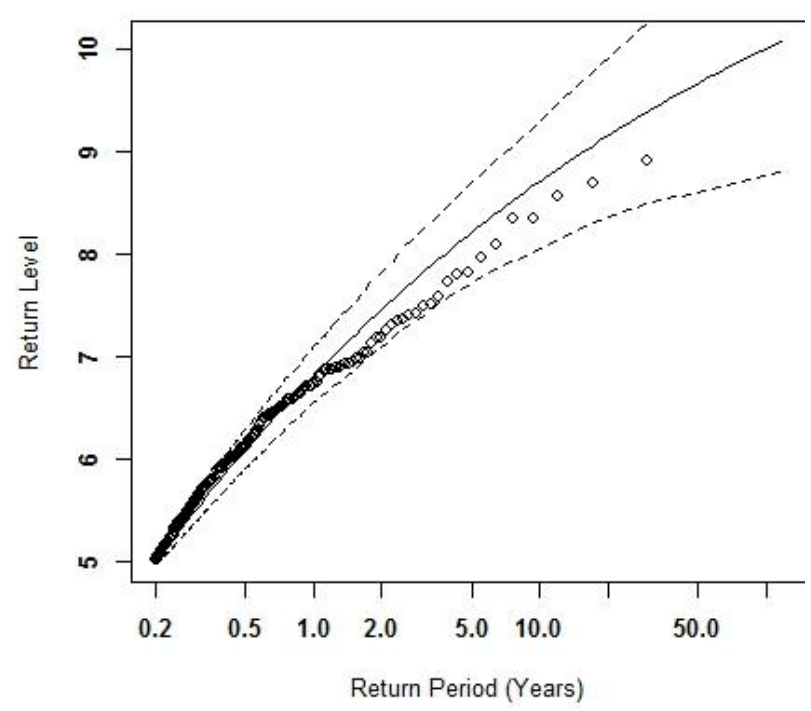

(b)

Fig. 28 :(a) Density plot of GPD model for ERA 46050 POT data from MLE method

(b) Return level plot of GPD model for ERA 46050 POT data from MLE method 


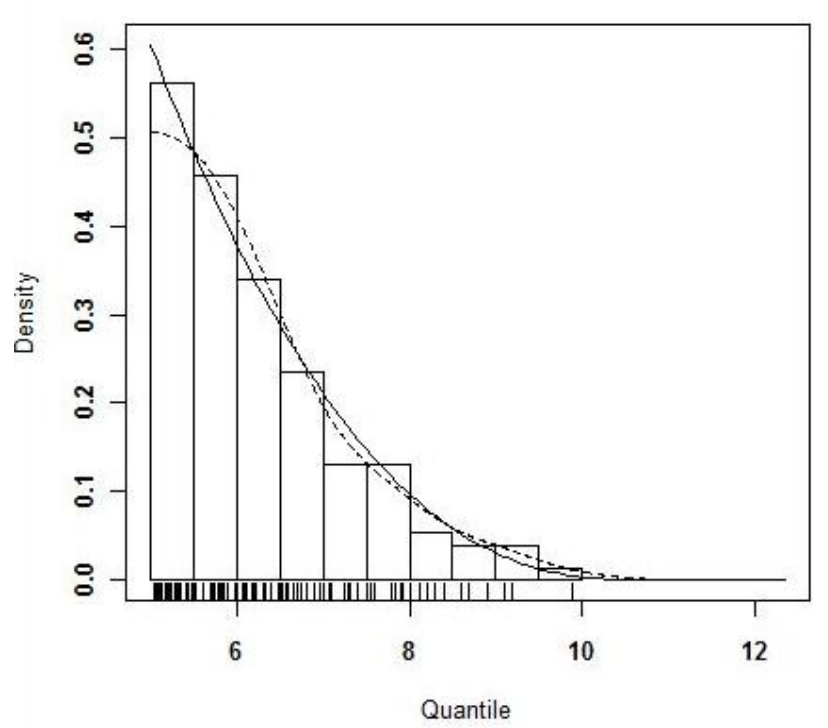

(a)

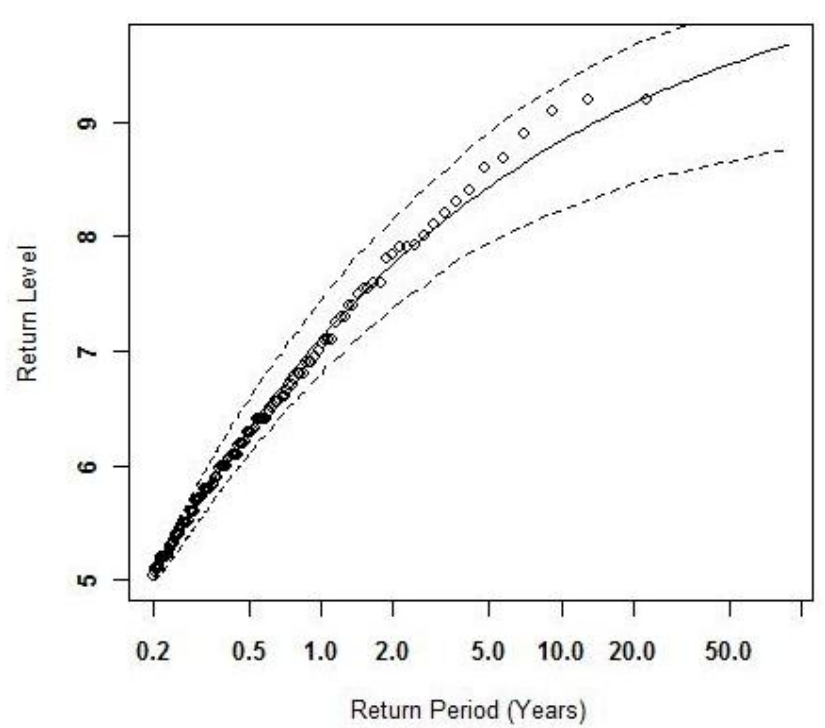

(b)

Fig. 29 :(a) Density plot of GPD model for Alghero Buoy POT data from PWM method

(b) Return level plot of GPD model for Alghero Buoy POT data from PWM method

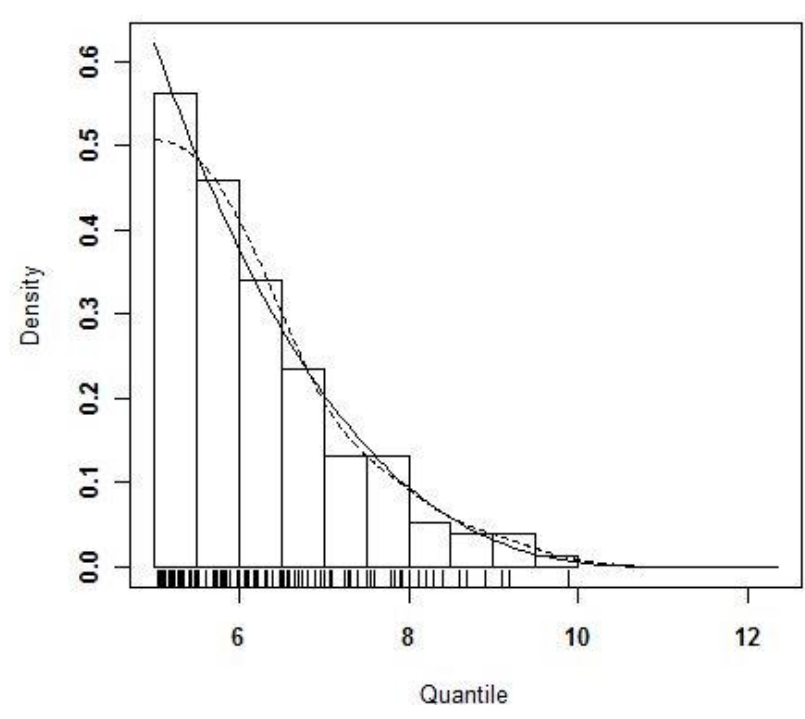

(a)

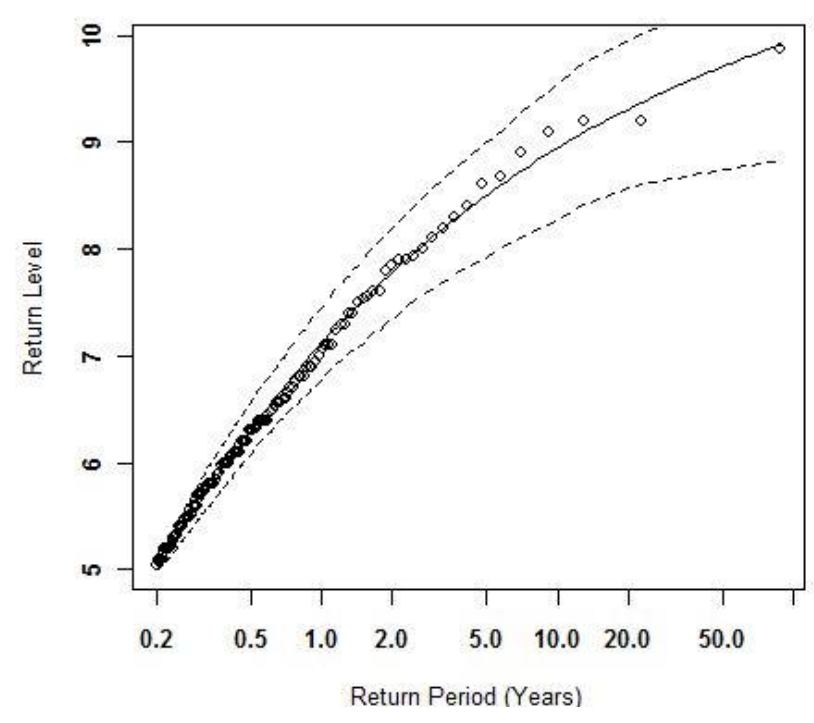

(b)

Fig. 30 :(a) Density plot of GPD model for Alghero Buoy POT data from MLE method

(b) Return level plot of GPD model for Alghero Buoy POT data from MLE method 


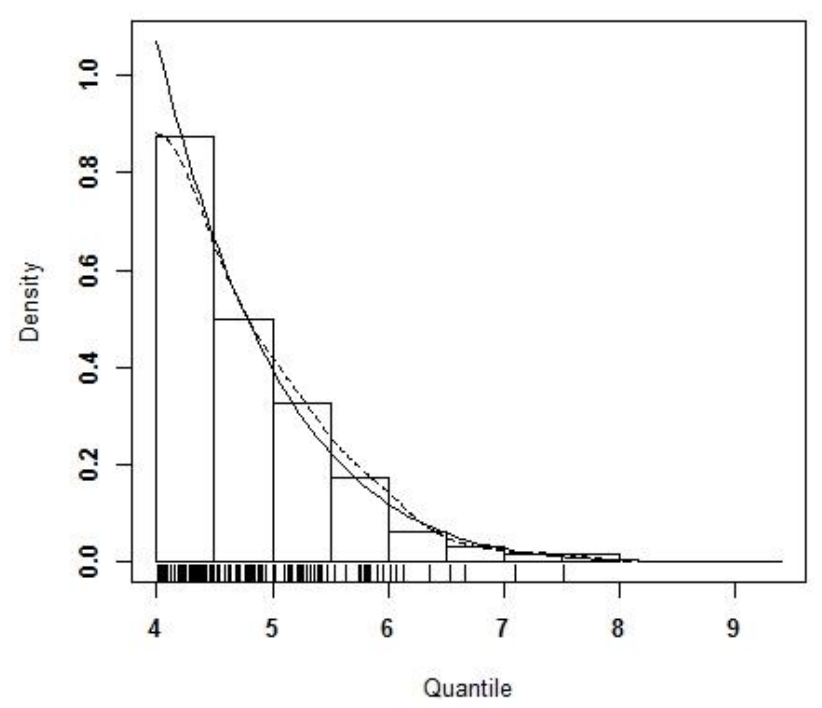

(a)

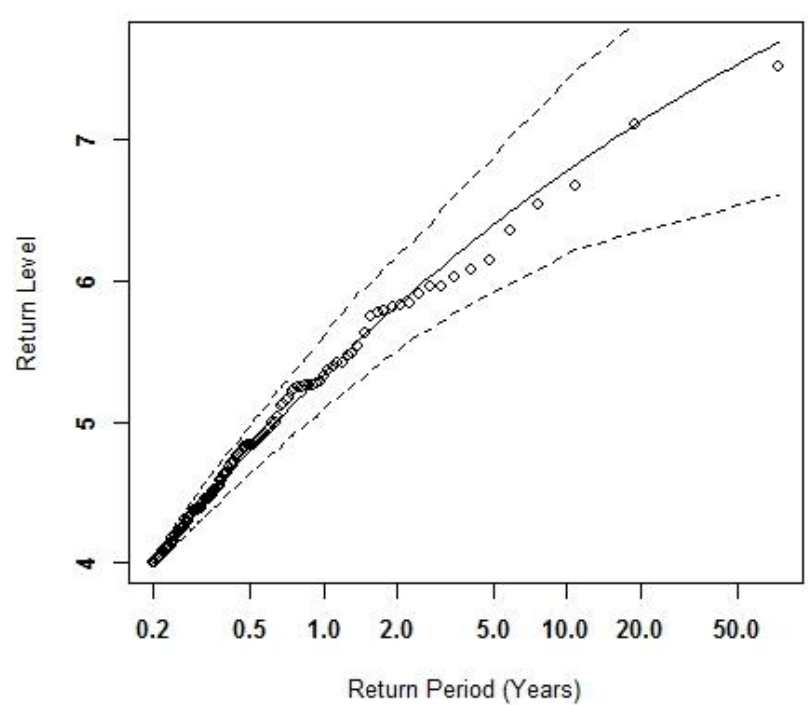

(b)

Fig. 31 :(a) Density plot of GPD model for ERA Alghero POT data from PWM method

(b) Return level plot of GPD model for ERA Alghero POT data from PWM method

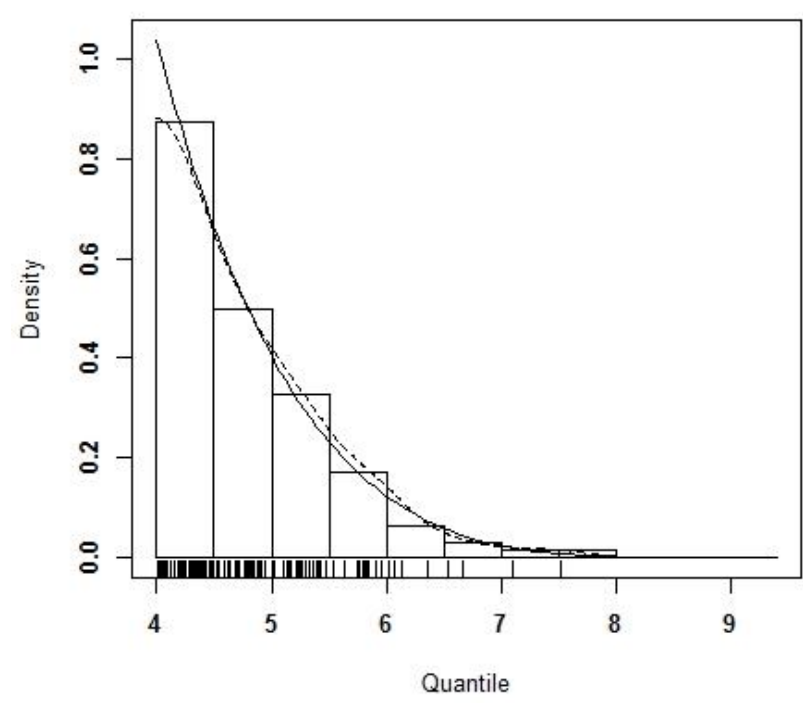

(a)

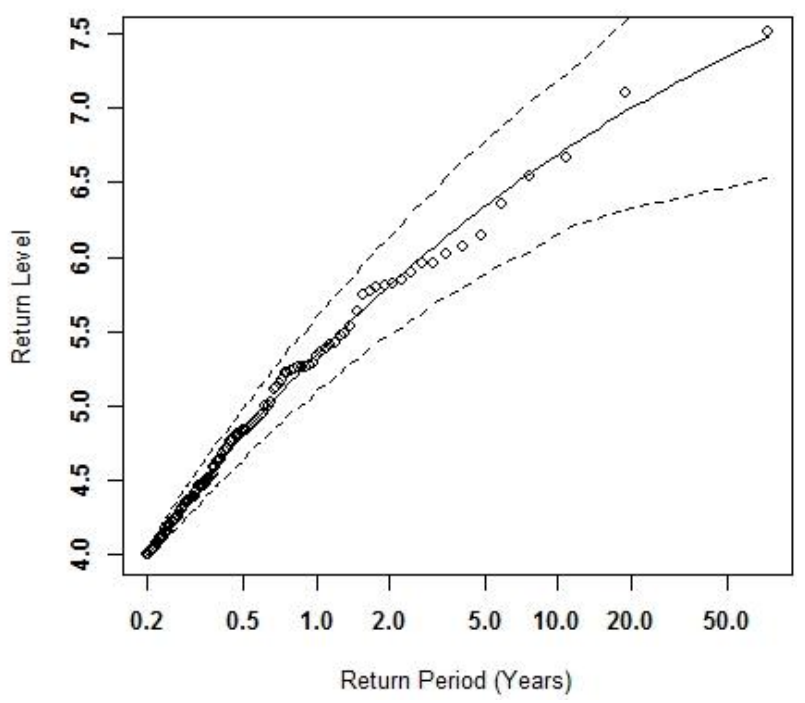

(b)

Fig. 32 : (a) Density plot of GPD model for ERA Alghero POT data from MLE method

(b) Return level plot of GPD model for ERA Alghero POT data from MLE method 


\section{POLYNOMIAL APPROXIMATION METHOD ANALYSIS}

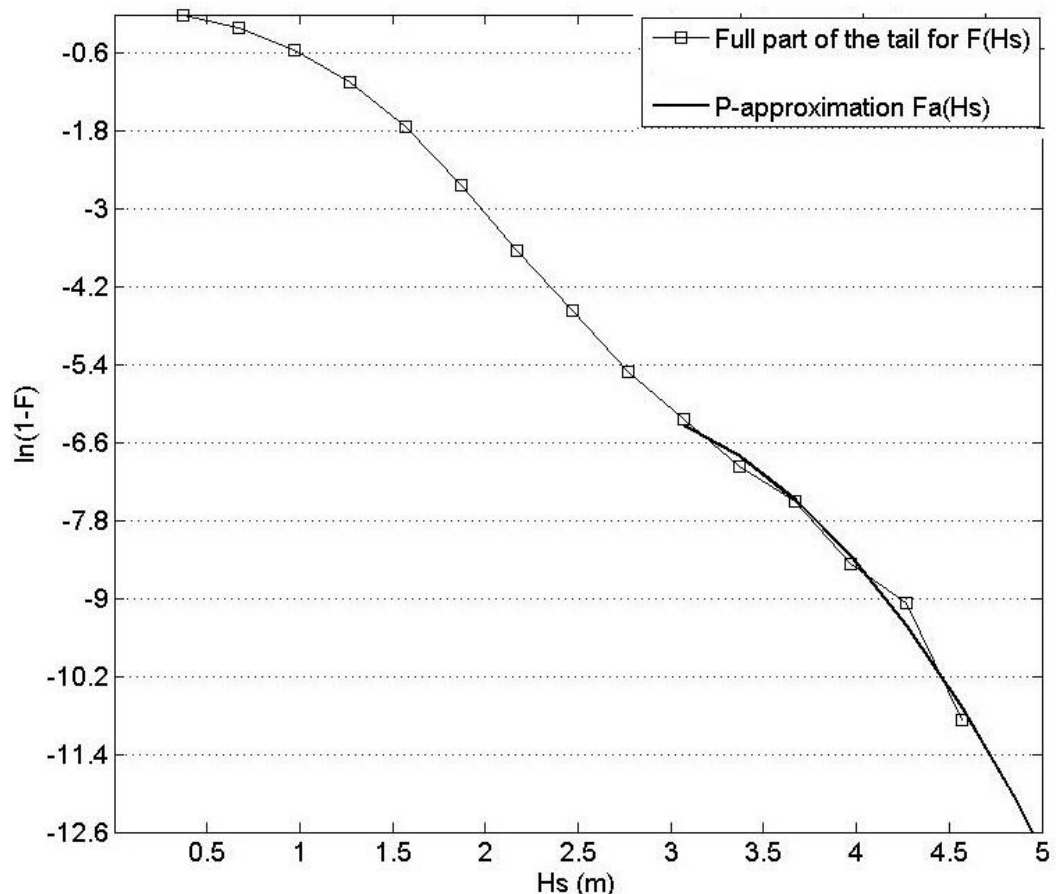

Fig. 5.51: Polynomial approximation method application for $H_{s}$ at ERA IN-1 with parameters: $N_{T}=6, n=2$

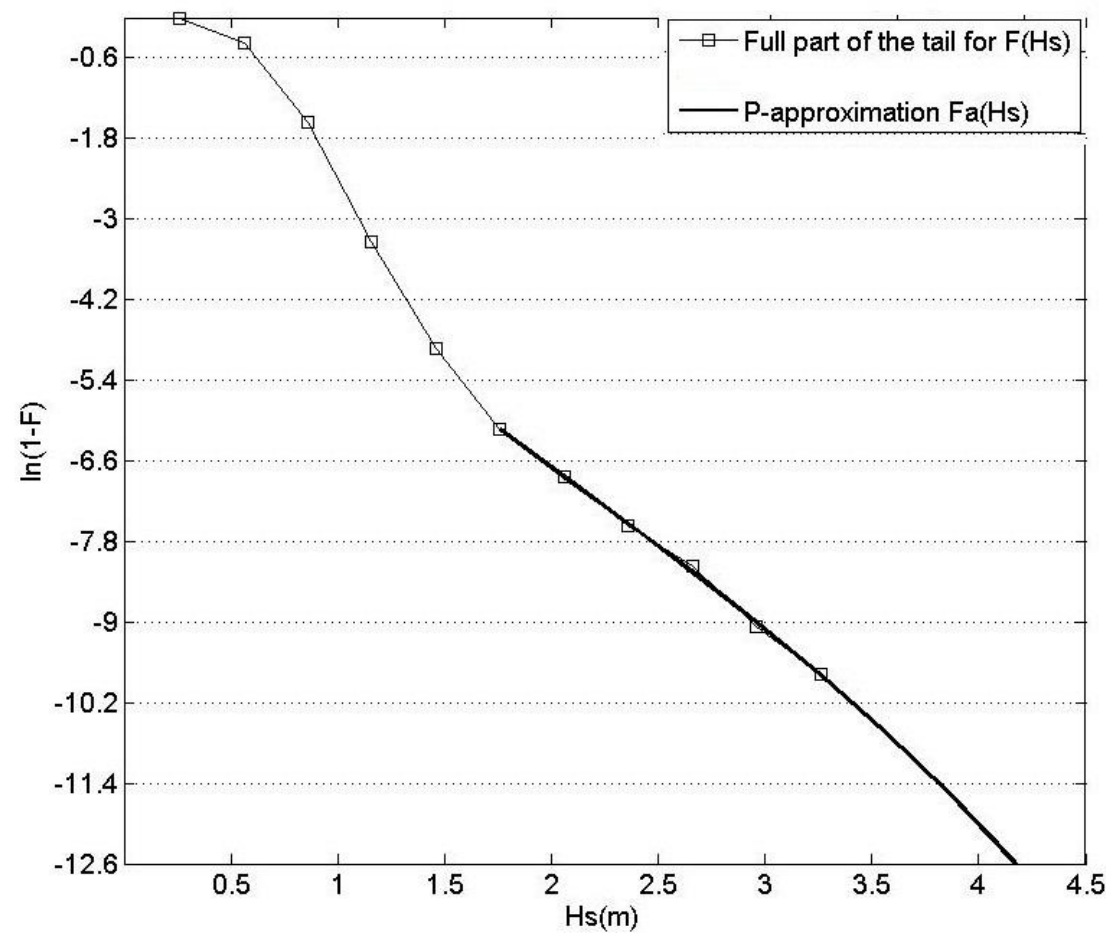

Fig. 5.52: Polynomial approximation method application for $H_{s}$ at ERA IN-2 with parameters: $N_{T}=6, n=3$ 


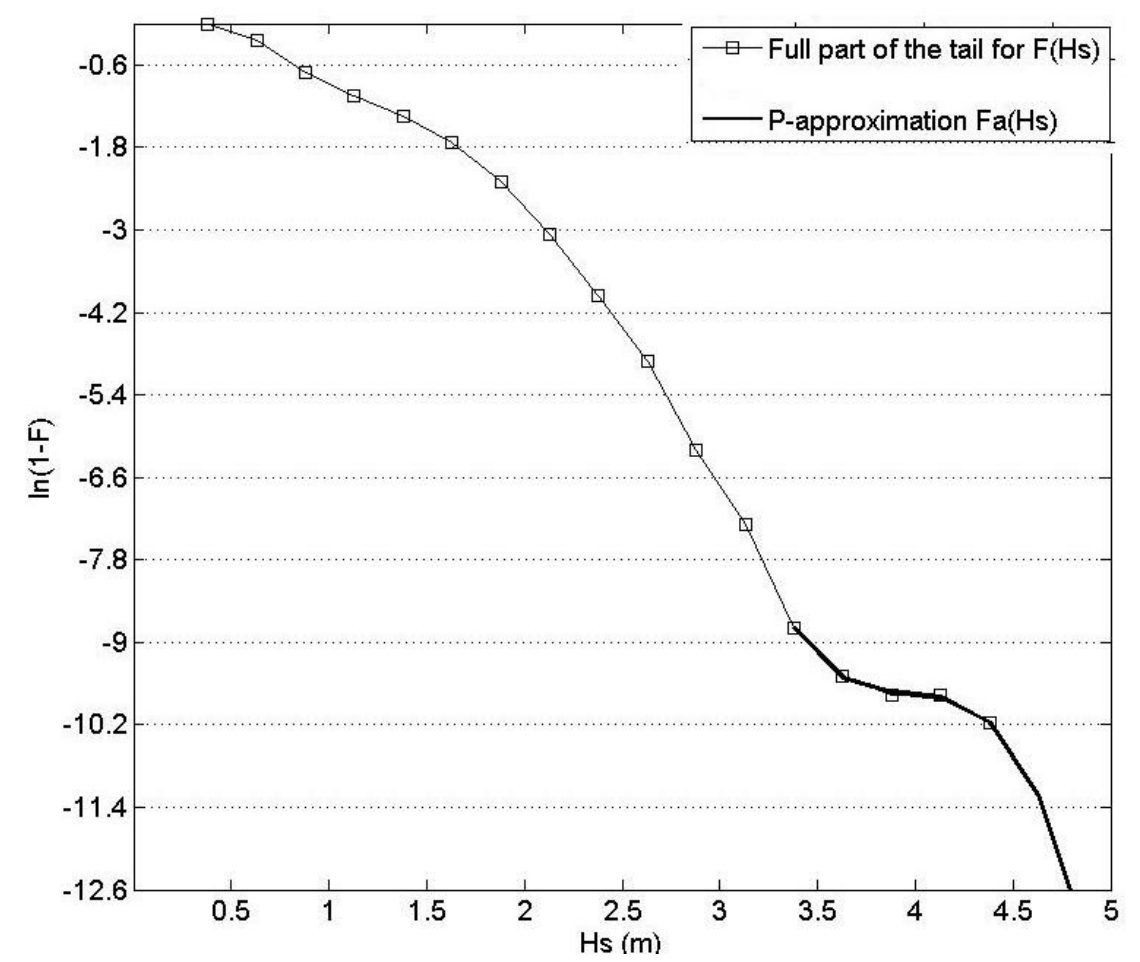

Fig. 5.53: Polynomial approximation method application for $H s$ at ERA IN-3 with parameters: $N_{T}=5, n=3$

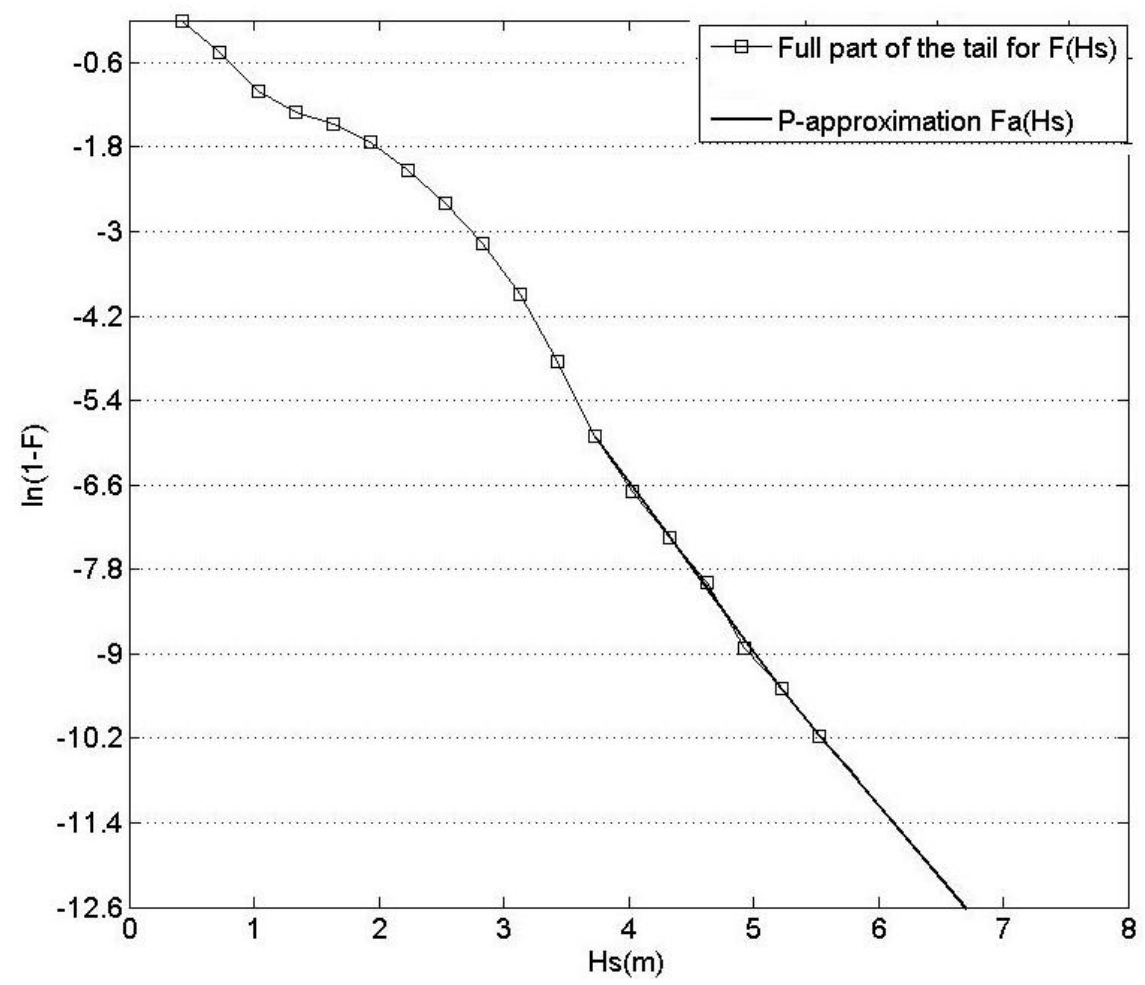

Fig. 5.54: Polynomial approximation method application for $H s$ at ERA IN-4 with parameters: $N_{T}=7, n=2$ 


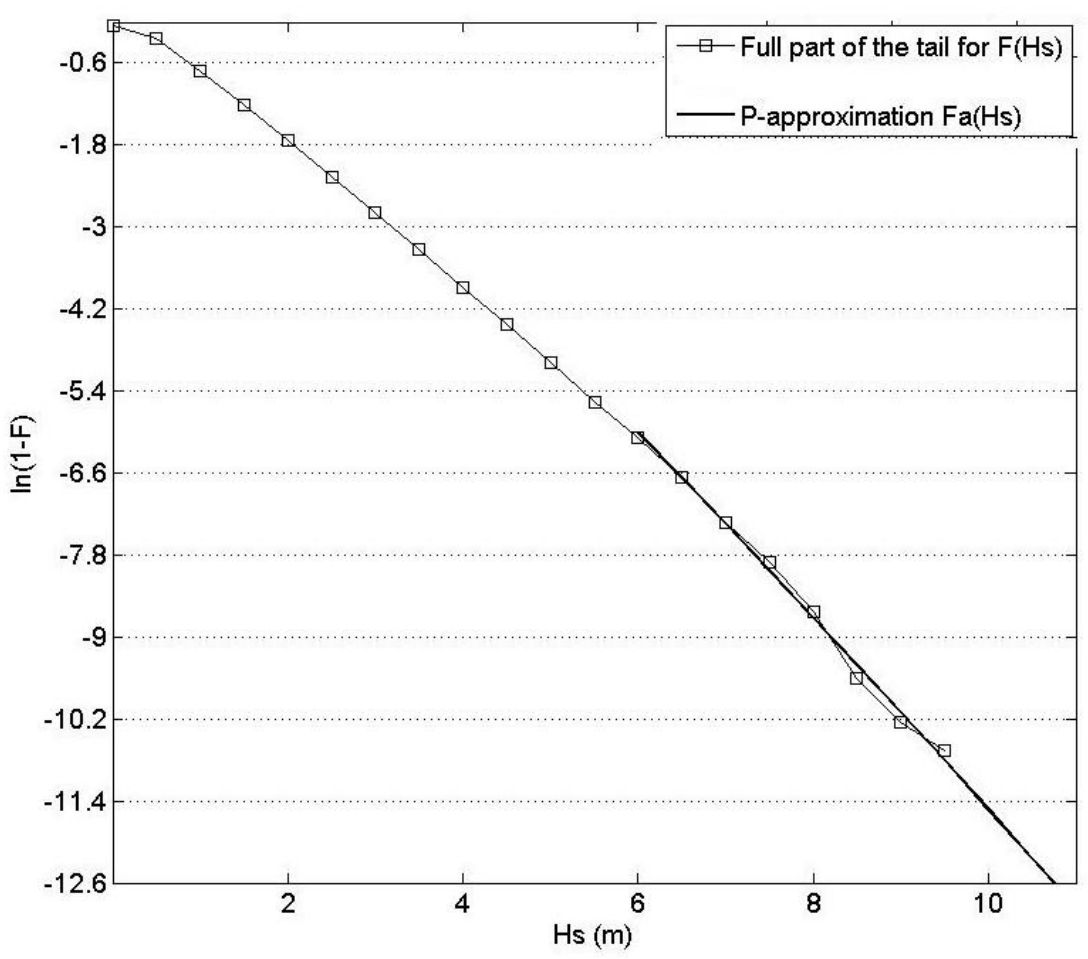

Fig. 5.55: Polynomial approximation method application for $H s$ at NOAA44005 with parameters: $N_{T}=8, n=2$

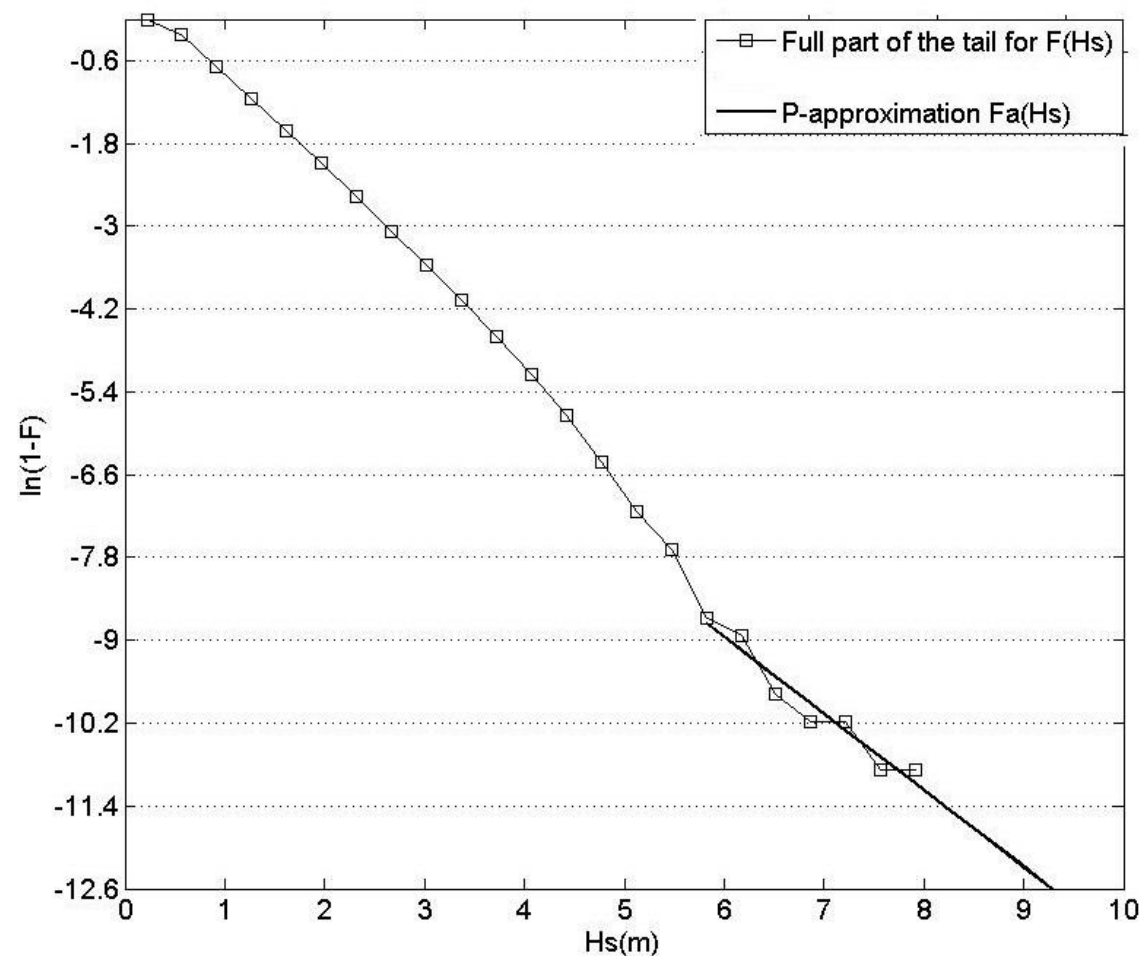

Fig. 5.56: Polynomial approximation method application for $H s$ at ERA44005 with parameters: $N_{T}=7, n=1$ 


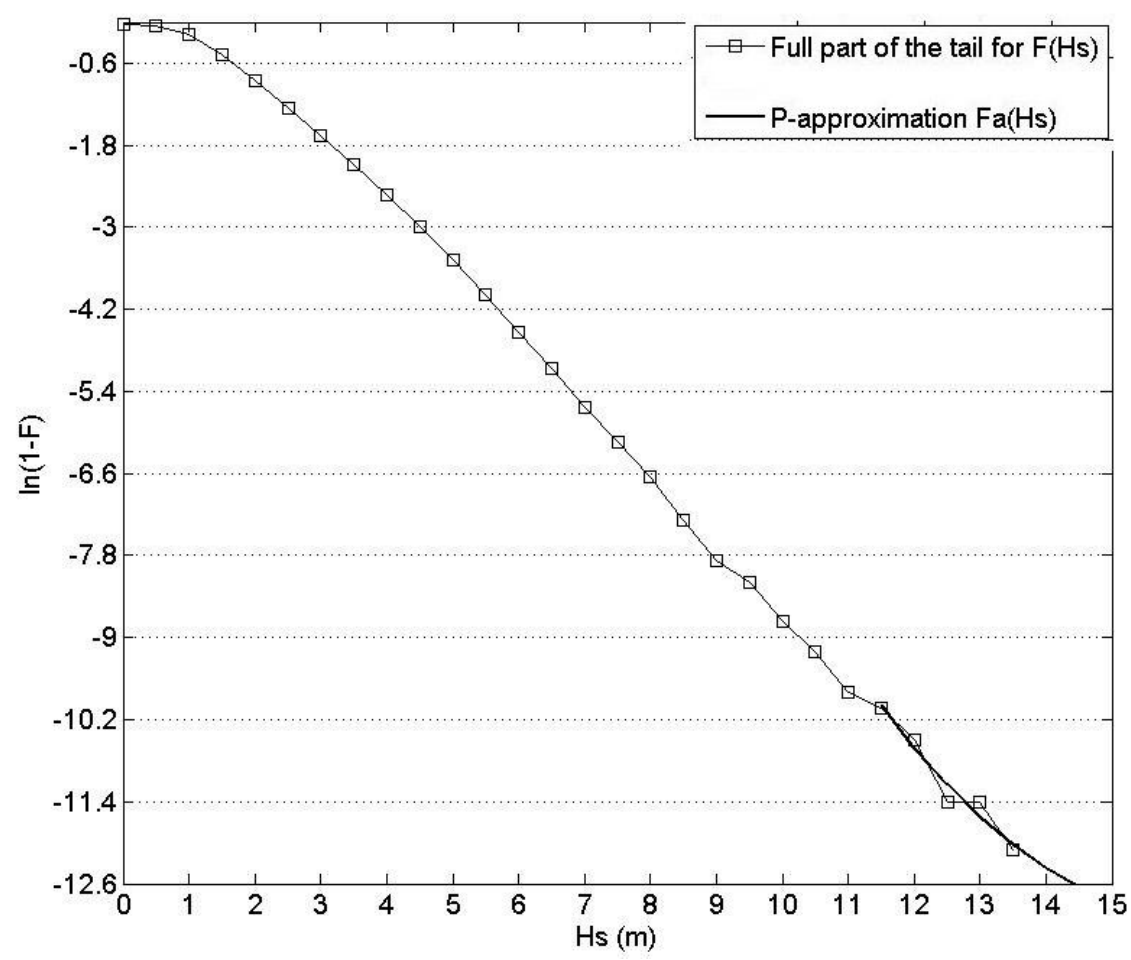

Fig. 5.57: Polynomial approximation method application for $H s$ at NOAA 46050 with parameters: $N_{T}=5, n=2$

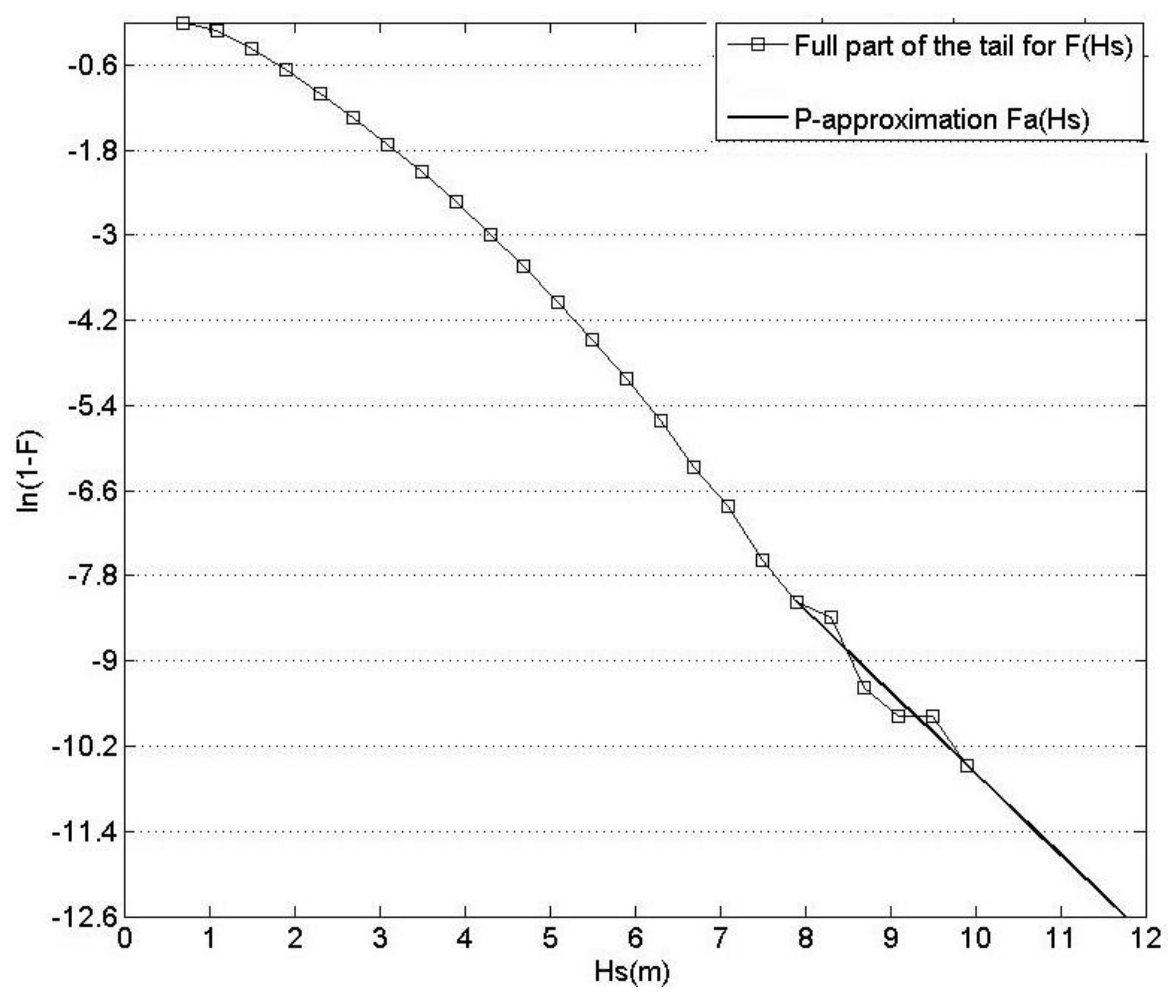

Fig. 5.58: Polynomial approximation method application for $H s$ at ERA 46050 with parameters: $N_{T}=6, n=1$ 


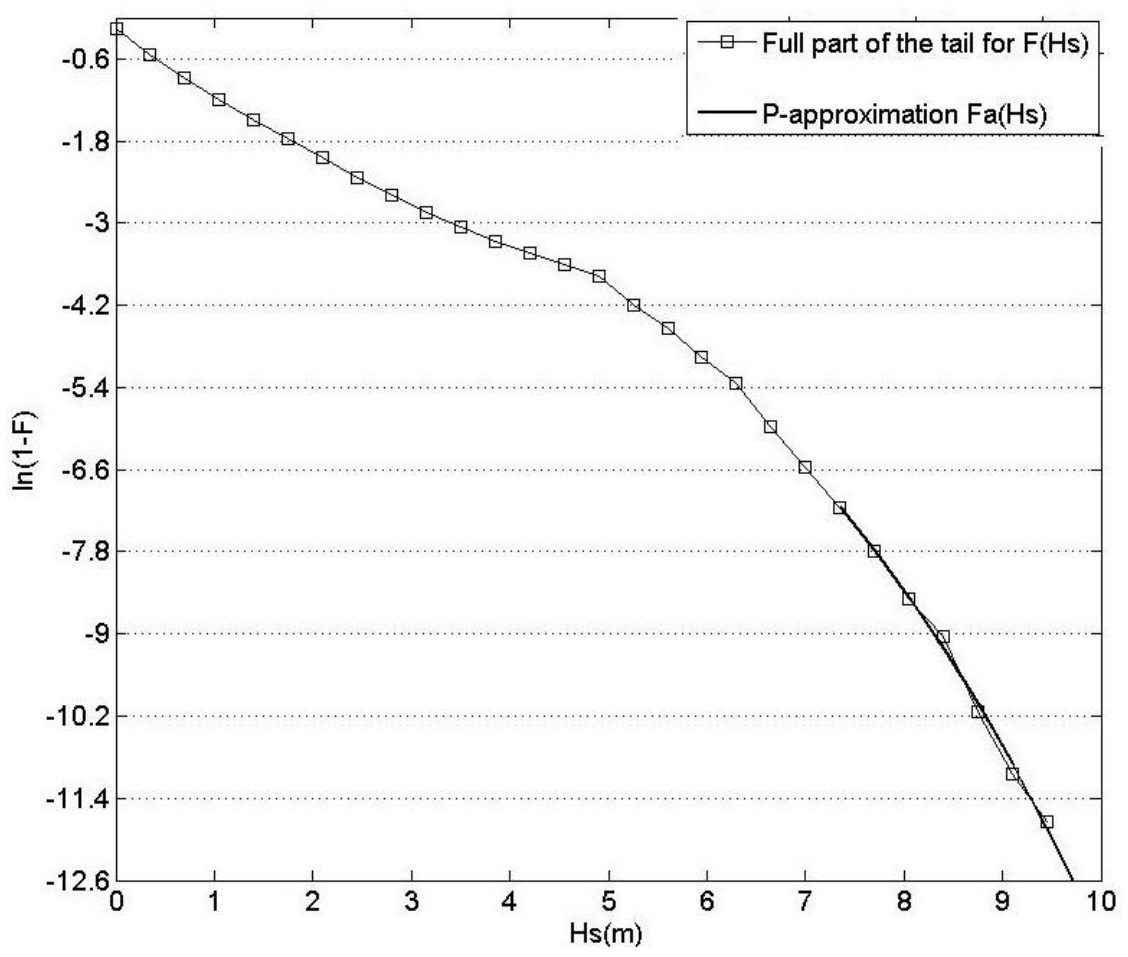

Fig. 5.59: Polynomial approximation method application for $H s$ at Alghero buoy with parameters: $N_{T}=7, n=2$

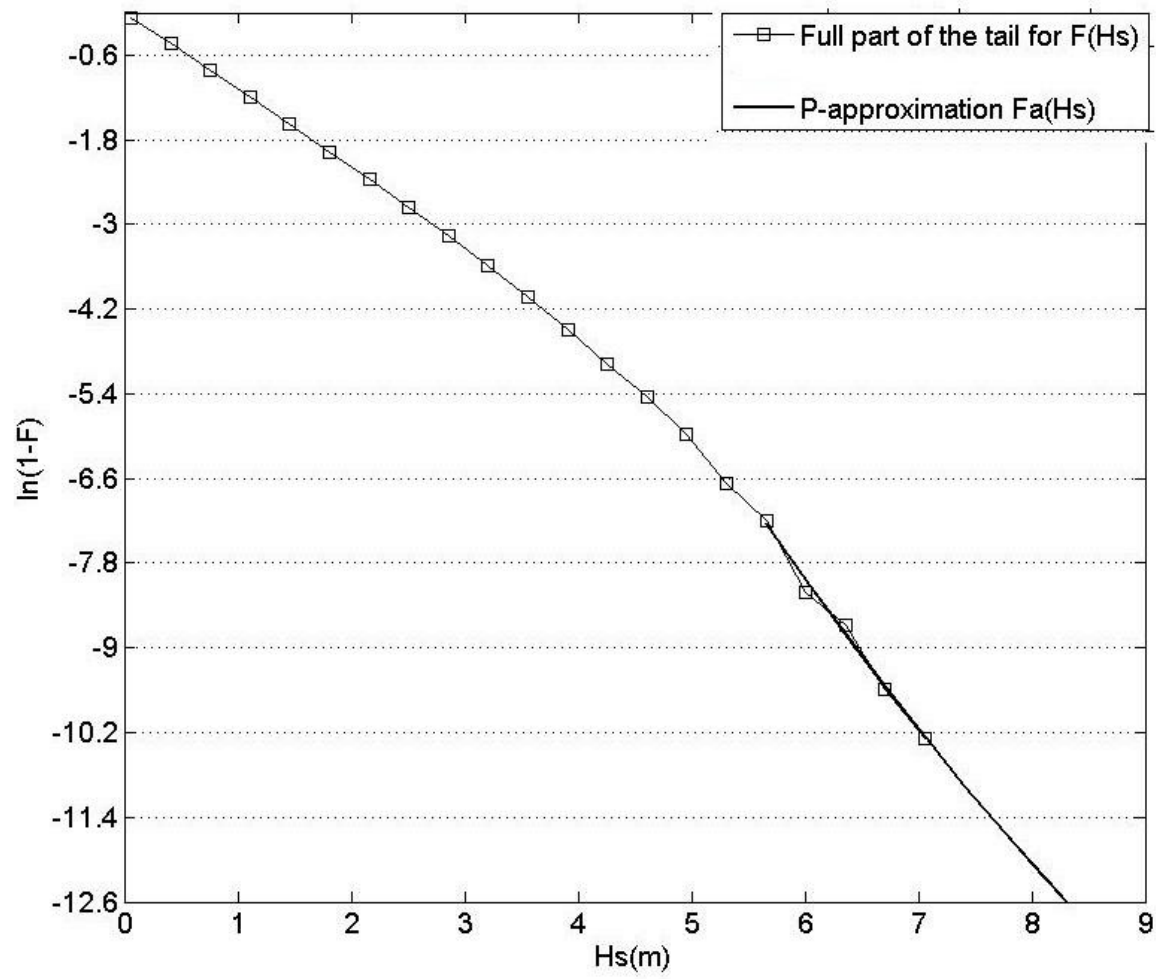

Fig. 5.60: Polynomial approximation method application for $H s$ at Alghero buoy with parameters: $N_{T}=5, n=2$ 


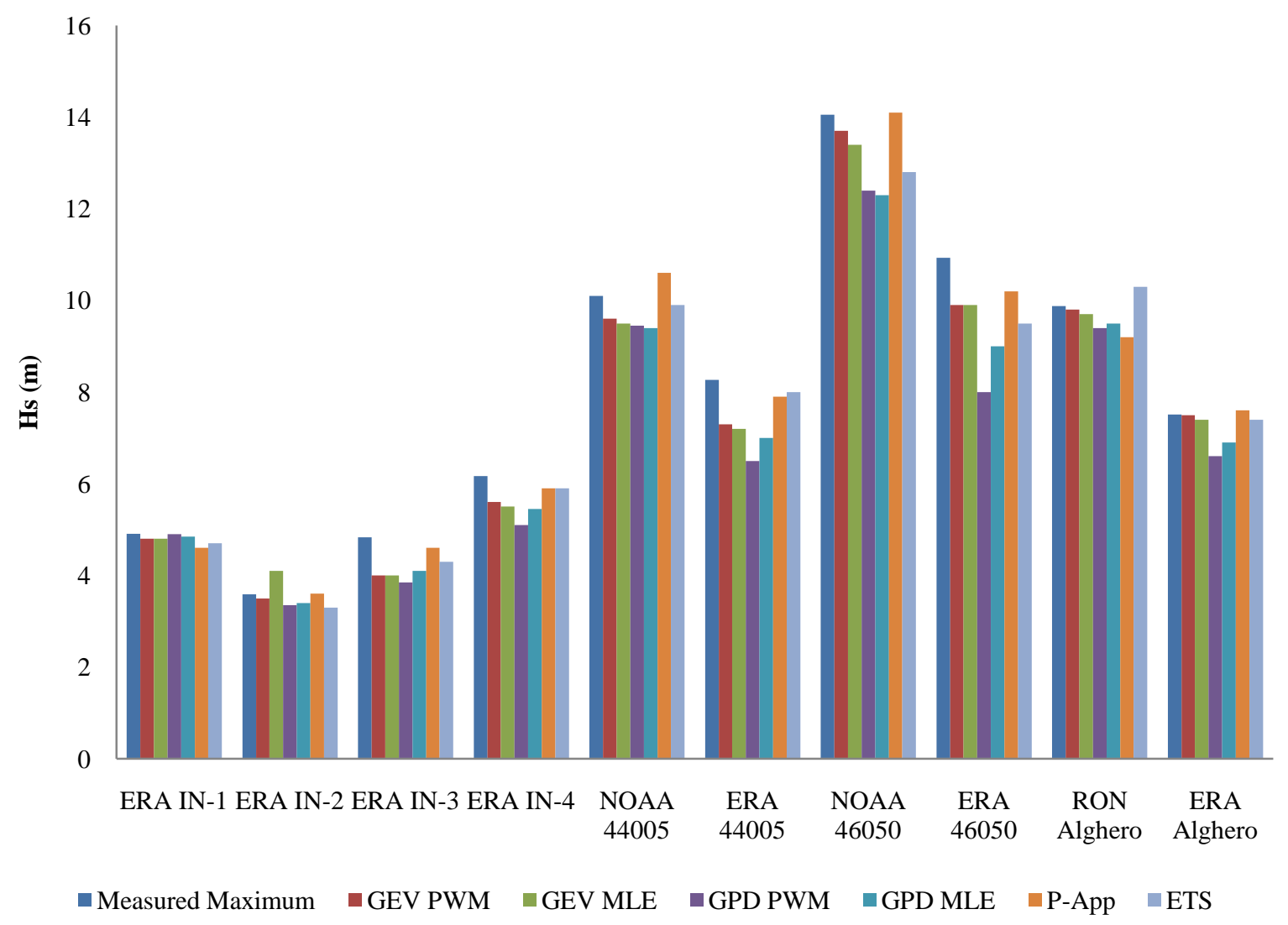

Fig. 3: Comparison of 30-yr values from different estimation models

Table 1: Percentage of variation of 30 year return value estimates from measured maximum wave height $(\%)$

\begin{tabular}{|c|c|c|c|c|c|c|}
\hline \multirow{2}{*}{ Data } & \multicolumn{2}{|c|}{ GEV } & \multicolumn{2}{c|}{ GPD } & \multirow{2}{*}{ P-App } & \multirow{2}{*}{ ETS } \\
\cline { 2 - 6 } ERA IN-1 & PWM & MLE & PWM & MLE & & \\
\hline ERA IN-2 & -2 & -2 & 0 & -2 & -6 & -4 \\
\hline ERA IN-3 & -17 & -17 & -19 & -15 & -5 & -11 \\
\hline ERA IN-4 & -9 & -11 & -17 & -11 & -4 & -4 \\
\hline NOAA 44005 & -5 & -6 & -6 & -7 & 5 & -2 \\
\hline ERA 44005 & -12 & -13 & -21 & -15 & -4 & -3 \\
\hline NOAA 46050 & -2 & -5 & -12 & -12 & 0 & -9 \\
\hline ERA 46050 & -9 & -9 & -27 & -18 & -7 & -13 \\
\hline RON Alghero & -1 & -2 & -5 & -4 & -7 & 4 \\
\hline ERA Alghero & 0 & -1 & -12 & -8 & 1 & -1 \\
\hline
\end{tabular}




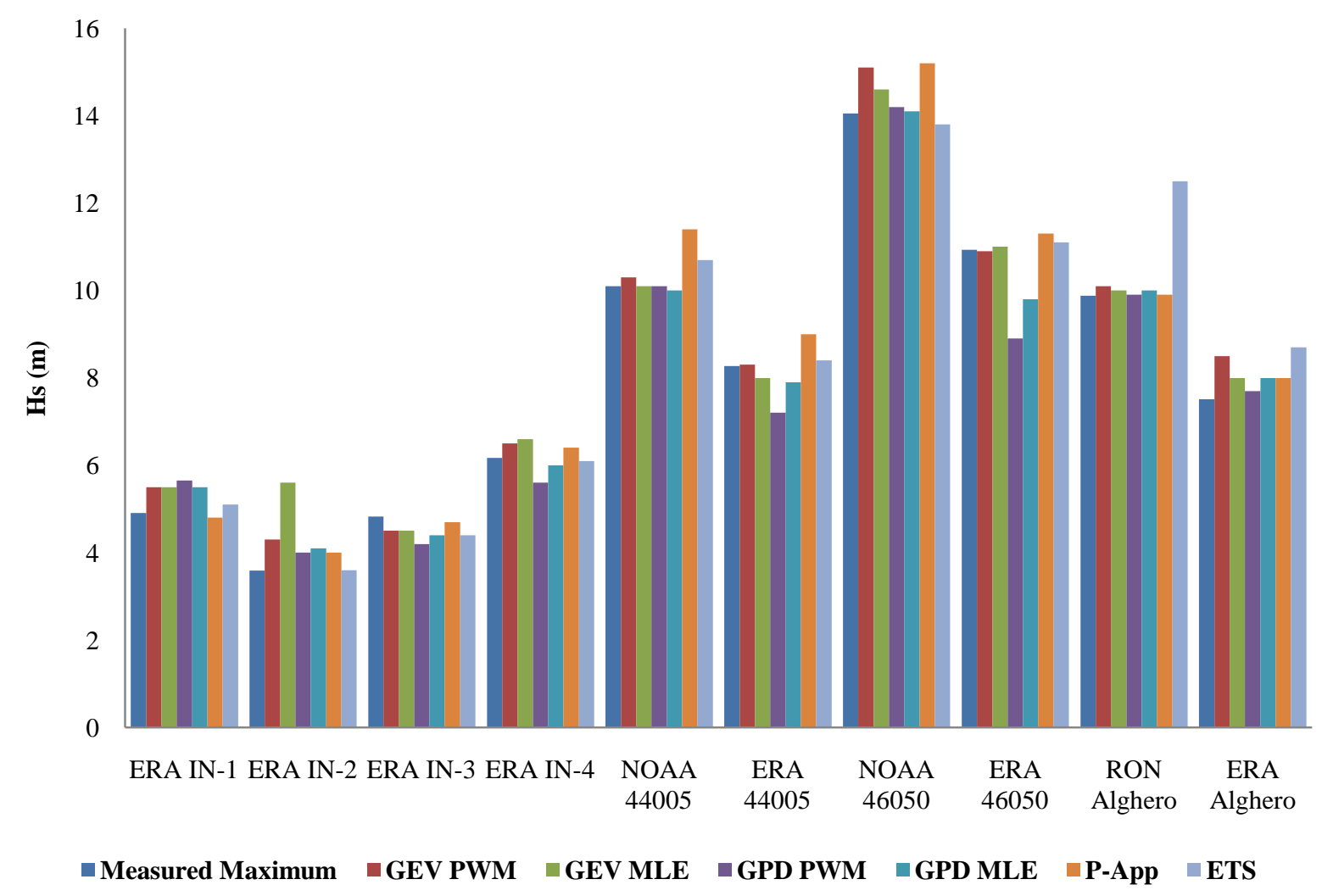

Fig. 4: Comparison of 100 year values from different estimation models

Table 2: Percentage of variation of 100 year return value estimates from measured maximum wave height $(\%)$

\begin{tabular}{|c|c|c|c|c|c|c|}
\hline \multirow{2}{*}{ Data } & \multicolumn{2}{|c|}{ GEV } & \multicolumn{2}{c|}{ GPD } & \multirow{2}{*}{ P-App } & \multirow{2}{*}{ ETS } \\
\cline { 2 - 6 } & PWM & MLE & PWM & MLE & & \\
\hline ERA IN-1 & 12 & 12 & 15 & 12 & -2 & 4 \\
\hline ERA IN-2 & 20 & 56 & 11 & 14 & 11 & 0 \\
\hline ERA IN-3 & -7 & -7 & -13 & -9 & -3 & -9 \\
\hline ERA IN-4 & 5 & 7 & -9 & -3 & 4 & -1 \\
\hline NOAA 44005 & 2 & 0 & 0 & -1 & 13 & 6 \\
\hline ERA 44005 & 0 & -3 & -13 & -4 & 9 & 2 \\
\hline NOAA 46050 & 7 & 4 & 1 & 0 & 8 & -2 \\
\hline ERA 46050 & 0 & 1 & -19 & -10 & 3 & 2 \\
\hline RON Alghero & 2 & 1 & 0 & 1 & 0 & 27 \\
\hline ERA Alghero & 13 & 7 & 3 & 7 & 7 & 16 \\
\hline
\end{tabular}


